Review

\title{
Combination of vitamin D and dipeptidyl peptidase-4 inhibitors (VIDPP-4i) as an immunomodulation therapy for autoimmune diabetes
}

\author{
Marcelo Maia Pinheiro $^{\mathrm{a}, \mathrm{b}, *}$, Felipe Moura Maia Pinheiro ${ }^{\mathrm{c}}$, Susana Nogueira Diniz ${ }^{\mathrm{b}}$, \\ Andrea Fabbri ${ }^{\mathrm{d}}$, Marco Infante ${ }^{\mathrm{d}, \mathrm{e}, \mathrm{f}, \mathrm{*}}$ \\ ${ }^{a}$ UNIVAG, University Center, Dom Orlando Chaves Ave, 2655 - Cristo Rei, Várzea Grande, 78118-000 Mato Grosso, Brazil \\ ${ }^{\mathrm{b}}$ Universidade Anhanguera de São Paulo - SP, 3305, Raimundo Pereira de Magalhães Ave., Pirituba, São Paulo, 05145-200 São Paulo, Brazil \\ ${ }^{\mathrm{c}}$ Hospital de Base, Faculdade de Medicina de São José do Rio Preto FAMERP - SP, 5546, Brigadeiro Faria Lima Ave, Vila São Pedro, São José do Rio Preto, 15015-50o \\ São Paulo, Brazil \\ ${ }^{\mathrm{d}}$ Diabetes Research Institute Federation (DRIF), Division of Endocrinology and Diabetes, CTO Andrea Alesini Hospital, ASL Roma 2, Department of Systems Medicine, \\ University of Rome Tor Vergata, Via San Nemesio 21, 00145 Rome, Italy \\ ${ }^{\mathrm{e}}$ UniCamillus, Saint Camillus International University of Health Sciences, Via di Sant'Alessandro, 8, 00131 Rome, Italy \\ ${ }^{\mathrm{f}}$ Network of Immunity in Infection, Malignancy and Autoimmunity (NIIMA), Universal Scientific Education and Research Network (USERN), Via San Nemesio 21, \\ 00145 Rome, Italy
}

\section{A R T I C L E I N F O}

\section{Keywords:}

Type 1 diabetes

LADA

Vitamin D

DPP-4 inhibitors

Immunomodulation

Immunotherapy

VIDPP-4i

\begin{abstract}
A B S T R A C T
Type 1 diabetes (T1D) and latent autoimmune diabetes in adults (LADA) represent the most common types of autoimmune diabetes and are characterized by different age of onset, degrees of immune-mediated destruction of pancreatic beta cells and rates of disease progression towards insulin dependence. Several immunotherapies aimed to counteract autoimmune responses against beta cells and preserve beta-cell function are currently being investigated, particularly in T1D. Preliminary findings suggest a potential role of combination therapy with vitamin D and dipeptidyl peptidase-4 (DPP-4) inhibitors (VIDPP-4i) in preserving beta-cell function in autoimmune diabetes. This manuscript aims to provide a comprehensive overview of the immunomodulatory properties of vitamin D and DPP-4 inhibitors, as well as the rationale for investigation of their combined use as an immunomodulation therapy for autoimmune diabetes.
\end{abstract}

\section{Introduction}

Autoimmune diabetes is a highly heterogeneous disease which can occur at any age [1]. Type 1 diabetes (T1D) and latent autoimmune diabetes in adults (LADA) represent the most common types of autoimmune diabetes, although other rare forms or subgroups of autoimmune diabetes have also been described, such as fulminant T1D and checkpoint inhibitor-associated autoimmune diabetes [2,3].

\subsection{Type 1 diabetes (T1D)}

T1D is an organ-specific autoimmune disease characterized by the immune-mediated destruction of insulin-secreting pancreatic beta cells, which ultimately results in lifelong dependence on exogenous insulin [4]. Even though beta-cell-targeted autoimmune responses are known to occur in T1D, the exact aetiology and pathological mechanisms are still not clear [5]. T1D is a complex multifactorial disease in which both genetic susceptibility and environmental factors promote the autoimmune responses against beta cells [5]. Several environmental risk factors have been suggested as candidate triggers of islet autoimmunity, including certain viruses (particularly enteroviruses), higher birthweight, infant weight gain, dysbiosis of the gut microbiota and various dietary factors (e.g., vitamin D deficiency, omega-3 fatty acid deficiency, high milk consumption) [6-10].

Although T1D onset usually occurs in children or young adults, the disease can occur at any age [5]. The process of pancreatic islet infiltration by immune cells (also known as "insulitis") represents the histological hallmark of the autoimmune destruction of beta cells within the pancreatic islets [11]. Even though CD8+ cytotoxic T lymphocytes are the most frequent amongst the islet infiltrating immune cells, CD4+ $\mathrm{T}$ lymphocytes (also known as T helper cells or Th cells), B lymphocytes and macrophages are also found, especially in young children $[5,12]$.

\footnotetext{
* Corresponding authors at: UniCamillus, Saint Camillus International University of Health Sciences, Via di Sant'Alessandro, 8, 00131 Rome, Italy (M. Infante).

E-mail addresses: marcelo.pinheiro@univag.edu.br (M.M. Pinheiro), marco.infante@unicamillus.org, marco.infante@uniroma2.it (M. Infante).
} 
Autoreactive CD8 + T cells recognize major histocompatibility complex (MHC) class I-restricted islet autoantigens on beta-cell surface and exert cytotoxic effects through a number of effector mediators, particularly cytokines released by $\mathrm{T}$ helper type 1 (Th1) cells such as interferon (IFN)- $\gamma[5,13]$. Evidence also suggests an important role of Th17 cells and follicular helper T cells in T1D pathophysiology [14]. Furthermore, several studies demonstrated that patients with T1D exhibit defects in the ability of regulatory $\mathrm{T}$ cells (Tregs) to suppress the activity and proliferation of autoreactive CD4+ and CD8+ T cells [15-18].

The starting point in the natural history of T1D is represented by genetic susceptibility to the disease, which is subsequently followed by three distinct stages, namely:

- stage 1 (islet autoimmunity): this stage is characterized by the development of beta-cell autoimmunity, as evidenced by the presence of at least two islet autoantibodies among glutamic acid decarboxylase autoantibodies (GADA), zinc transporter 8 autoantibodies (ZnT8A), insulin autoantibodies (IAA), insulinoma-associated antigen-2 autoantibodies (IA-2A); during this stage, subjects remain normoglycemic and asymptomatic.

- stage 2 (abnormal glucose tolerance): subjects maintain multiple islet autoantibody positivity and remain asymptomatic, but display dysglycemia, as evidenced by impaired fasting glucose levels, abnormal oral glucose tolerance test, or glycated hemoglobin (HbA1c) $\geq 5.7 \%$

- stage 3 (symptomatic disease): this stage is characterized by the onset of clinical T1D, which is often accompanied by symptoms such as polyuria, polydipsia, fatigue, weight loss, and diabetic ketoacidosis [19].

Shortly after the clinical onset of the disease and the initiation of insulin therapy, most subjects with T1D (approximately two-thirds) experience a transient and partial spontaneous remission phase (also referred to as "honeymoon phase"), which is accompanied by a marked reduction in exogenous insulin requirements and near-normal glycemic control [20-23]. Conversely, complete remission (characterized by near-normal glucose control without need for insulin therapy) seldom occurs, being described in approximately $2-12 \%$ of young T1D subjects in some population-based cohort studies [21]. Overall, duration of remission phase varies widely between individuals, with an average of approximately 7 months [24]. It has been suggested that both immune and metabolic factors contribute to the beta-cell recovery observed during the honeymoon phase, including transient development of antigen-specific adaptive immune tolerance, optimized glucose control, improved insulin sensitivity, as well as reduced glucotoxicity following the initiation of insulin therapy [20,25].

\subsection{Latent autoimmune diabetes in adults (LADA)}

LADA is a distinct form of autoimmune diabetes characterized by an older age of onset, a less severe immune-mediated destruction and functional deterioration of beta cells, and a slower progression towards insulin dependence compared to T1D [1]. Assessment of the pathology of pancreata obtained from LADA patients revealed that this disease represents a milder and more slowly progressing form of autoimmune diabetes compared to T1D. This is strongly suggested by various findings, such as increased beta-cell proliferation capacity, increased antiinflammatory capacity (as documented by the increase of interleukin [IL]-10 gene expression), reduced beta-cell proapoptotic signaling, and predominance of IL- $1 \beta$ in the immune cell infiltrate as compared to the predominance of tumor necrosis factor (TNF)- $\alpha$ observed in T1D pancreata [26].

Current criteria for diagnosing LADA include: i) adult age of onset (greater than 30 years); ii) presence of any islet cell autoantibody; and iii) absence of insulin requirement for at least 6 months after diagnosis $[1,27,28]$. Compared to T1D, LADA displays a greater clinical heterogeneity and shares clinical and metabolic features with both T1D and type 2 diabetes (T2D). In fact, patients with LADA exhibit a remarkable variability in the rate of beta-cell destruction, different degrees of insulin resistance and heterogeneous patterns of islet autoimmunity, probably due to differences in genetic and immune factors [1]. For these reasons, LADA is often diagnosed and treated as T2D, potentially resulting in a more rapid progression towards insulin dependence. This aspect has relevant clinical implications, since optimal glucose control is critical to preserve beta-cell function and reduce the risk of chronic diabetes complications [1,29].

\section{Pathophysiology of autoimmune diabetes: Beyond the beta cell}

Although T1D has long been conceived as an autoimmune disease arising from the immune-mediated destruction of pancreatic beta cells, accumulating evidence over the last years has showed that T1D pathophysiology is more complex and involves also other relevant aspects, such as dysfunction of glucagon-secreting alpha cells and histological abnormalities of the exocrine pancreas. Notably, T1D patients often exhibit a dysregulated glucagon secretion by pancreatic alpha cells, consisting in: i) impaired ability of these cells to secrete glucagon in response to hypoglycemia, and/or ii) excessive postprandial glucagon secretion $[30,31]$. These alterations can substantially contribute to the occurrence of hyperglycemic and hypoglycemic episodes. Several factors account for the alpha-cell dysfunction occurring in T1D, including lack of beta-cell signaling, sympathetic islet neuropathy, as well as alterations in transcription factors constituting alpha-cell identity $[30,32,33]$. It has been shown that insulin-negative islets in subjects with T1D are dominated by glucagon-positive cells that often lack the alpha-cell transcription factor ARX, while instead expressing PDX1, which is normally only expressed in beta cells, suggesting a process of beta-cell dedifferentiation into alpha cells [34]. However, beta-cell neogenesis from alpha cells emanating from endocrine progenitor cells that reside within or adjacent to the ductal epithelium has also been suggested as a possible mechanism aimed to compensate for beta-cell loss in T1D. Therefore, it is challenging to establish whether the intermediate cell type (exhibiting some characteristics of alpha cells and some characteristics of beta cells) arises from beta-cell dedifferentiation or beta-cell neogenesis [34].

Histological abnormalities of the exocrine pancreas are common in patients with T1D. In particular, acinar atrophy, intralobular and interacinar fibrosis, leucocytic infiltration, fatty infiltration, pancreatic arteriosclerosis and focal lesions of acute pancreatitis are all frequently observed [35]. Vascular events and hemorrhages within pancreatic islets also occur in patients with T1D [36]. Periductal accumulation of leukocytes and fibrosis (the end stage of inflammation) might negatively affect islet neogenesis from endocrine progenitor cells residing within the periductal area [36]. Recently, it has been shown that patients with T1D exhibit a lower number of acinar cells and a greater degree of fibrosis within the pancreatic exocrine tissue [37]. The loss of pancreatic exocrine mass accounts for the smaller pancreas volume observed in patients with T1D compared to non-diabetic subjects [35,37]. Noteworthy, $25 \%$ to $75 \%$ of adult subjects with T1D show pancreatic exocrine dysfunction [35]. Various putative causal factors for such histological abnormalities have been proposed, such as: i) impaired secretion of insulin, glucagon, somatostatin and pancreatic polypeptide; ii) global pancreatic inflammation; iii) autoimmune responses targeting the exocrine pancreas; iv) vascular and neural abnormalities; and v) involvement of pancreatic stellate cells [35]. In light of these remarks, therapeutic strategies aimed to restore the disordered glucagon secretion and the histological abnormalities of the exocrine pancreas would be highly desirable interventions in the setting of autoimmune diabetes. 


\section{Heterogeneity of autoimmune diabetes}

The canonical notion that T1D results from the complete loss of beta cells leading to an absolute insulin deficiency [38] has recently been overcome. Indeed, emerging evidence shows that many patients with long-standing T1D exhibit the persistence of insulin-containing pancreatic islets and maintain some degree of endogenous insulin secretion even many decades after the diagnosis [39-42]. In this regard, it is worth considering that T1D is a highly heterogeneous disease in terms of immunopathological and clinical features [43]. Age at diagnosis is one of the main variables associated with the heterogeneous rate of decline in insulin secretion among subjects with T1D. In particular, younger age at onset of T1D is accompanied by lower residual beta-cell function [44,45], greater decline in endogenous insulin secretion $[46,47]$ and lower occurrence of the honeymoon phase $[20,24]$. Recently, Leete et al. [48] demonstrated the existence of two histologically distinct endotypes of T1D that correlate with age at diagnosis. By using pancreas samples recovered soon after T1D onset ( $<2$ years) from young people diagnosed at different ages $(<7$ years, $7-12$ years and $\geq$ 13 years), authors found that the younger group exhibited more pronounced aberrant proinsulin processing within insulin-containing islets, lower C-peptide levels and higher median proinsulin to C-peptide ratio compared to the group diagnosed at $\geq 13$ years [48]. These distinct patterns of residual insulin secretion appear to align with the previously described immune phenotypes (immunotypes) of T1D [12,49]. Similar findings have also been observed in patients with LADA. In this context, the LADA China Study 8 investigated whether age of onset of LADA contributes to the clinical heterogeneity of the disease by comparing clinical, metabolic and immunogenetic characteristics between elderly and young patients [50]. Interestingly, the study found that elderly LADA group (age of onset $\geq 60$ years) exhibited a better residual betacell function and a higher degree of insulin resistance compared to young LADA group (age of onset $<60$ years). Elderly LADA patients showed more proportion of low titre GADA and lower GADA titres compared to young LADA patients aged $<40$ years. Elderly LADA group also showed a clinical and genetic profile more similar to that of agematched subjects with T2D [50].

All the aforementioned remarks have important implications in the setting of immune interventions for autoimmune diabetes. Retention of residual endogenous insulin secretion has been associated with improved glucose control, reduced risk of hypoglycemia, lower glucose variability and fewer chronic diabetes complications in T1D [51-54]. Therefore, protection against immune-mediated beta-cell destruction and preservation of residual beta-cell mass and function (as measured by C-peptide, which is secreted from beta cells at an equimolar ratio to insulin) represent critical goals of clinical trials investigating the efficacy of disease-modifying agents and immunotherapies for autoimmune diabetes, including T1D and LADA $[1,55,56]$. So far, several immunotherapies have been investigated in new-onset T1D, although they have mostly showed no effect or only a transient beneficial effect in counteracting the progressive decline in beta-cell function [56]. Hence, the use of immunotherapeutic agents in a combination therapy approach is worth being tested in future clinical trials. Targeting multiple pathways involved in beta-cell loss and dysfunction (e.g. innate immunity, adaptive immunity, regulatory immunity, glucotoxicity) may represent a successful immune intervention for autoimmune diabetes [57]. Moreover, the clinical and immunopathological heterogeneity of autoimmune diabetes accounts, at least in part, for the interindividual variability in the response to different immunotherapies [58]. This aspect should be taken into account in future studies to facilitate the selection of targeted immunotherapies aimed to halt beta-cell autoimmunity and disease progression in selected subsets of individuals with autoimmune diabetes.

Over the last few years, our group and other authors showed a potential therapeutic role of dipeptidyl peptidase-4 inhibitors (DPP-4i) and/or vitamin $\mathrm{D}$ in prolonging the clinical remission phase and preserving the residual beta-cell function in patients with autoimmune diabetes [59-69]. This review aims to provide a comprehensive overview of the anti-inflammatory and immunomodulatory properties of vitamin D and DPP-4i, as well as their potential synergistic effects in preserving residual beta-cell function in autoimmune diabetes, including both T1D and LADA. In the text, we will use the term VIDPP-4i when referring to the combination therapy with vitamin D and DPP-4i.

\section{Vitamin D and immune system}

Vitamin D is a term that refers to a group of fat-soluble secosteroids, namely: i) ergocalciferol (vitamin D2), which is produced in response to ultraviolet irradiation of the phytosterol ergosterol found in fungal sources such as mushrooms and yeast, and ii) cholecalciferol (vitamin $\mathrm{D}_{3}$ ), which is synthesized in the human skin upon ultraviolet-B (UVB) light irradiation of the precursor 7-dehydrocholesterol (7-DHC). Although vitamin $\mathrm{D}$ is primarily produced in the skin upon sunlight exposure, it can also be obtained from a few external sources, such as fungal sources or animal foods containing ergocalciferol and cholecalciferol, respectively $[70,71]$. Once produced in the skin or ingested and absorbed through foods or dietary supplements, vitamin $\mathrm{D}_{3}$ is transported in the blood by vitamin D binding protein (DBP) to the liver, where it is converted into 25-hydroxyvitamin $\mathrm{D}_{3}\left[25(\mathrm{OH}) \mathrm{D}_{3}\right.$, also known as calcifediol] by the action of vitamin D-25-hydroxylase enzyme. Then, $25(\mathrm{OH}) \mathrm{D}_{3}$ is transported to the kidneys, where 1- $\alpha$-hydroxylase enzyme catalyzes its conversion into 1,25-dihydroxyvitamin $\mathrm{D}_{3}[1,25(\mathrm{OH}) 2 \mathrm{D} 3$; also referred to as calcitriol], which is the biologically active metabolite of vitamin $\mathrm{D}[70] .25(\mathrm{OH}) \mathrm{D}$ is the major circulating form of vitamin $\mathrm{D}$ and its serum levels represent the most reliable biomarker of vitamin D status [72,73].

Over the last years, a growing body of evidence showed that vitamin D exerts pleiotropic effects [74-78] other than the well-known regulation of calcium and bone homeostasis $[79,80]$. Remarkably, several preclinical and experimental studies demonstrated that calcitriol plays an important role in the regulation of innate and adaptive immune responses $[74,77,81,82]$. The first hint of the role of vitamin D in the maintenance of immune homeostasis came from the evidence that immune cells are both vitamin D targets and local producers of vitamin D. Vitamin D acts through a specific receptor known as vitamin D receptor (VDR), which is a member of the nuclear receptor/steroid hormone receptor superfamily. The actions of vitamin D are classified into: i) genomic, through the VDR-mediated transcriptional effects in the cell nucleus, and ii) non-genomic, when the VDR located on the cell membrane and/or cytoplasm induces rapid signaling pathways [83]. Functional VDR has been identified in almost all immune cells, including neutrophils, T lymphocytes and antigen-presenting cells (APCs), such as dendritic cells (DCs) and macrophages $[84,85]$. On the other hand, it has been shown that several immune cells (e.g., macrophages, DCs, T- and Blymphocytes) express the vitamin D-activating enzymes $25-$ and $1 \alpha$ hydroxylase [86-90]. Therefore, inactive vitamin D metabolites can be converted into the active form calcitriol within a local immunological milieu [81]. Importantly, calcitriol has been shown to exert several effects on innate and adaptive immune system, resulting in the activation of anti-inflammatory and immunomodulatory pathways and induction of immune tolerance. Calcitriol promotes monocyte and macrophage antimicrobial activity by inducing the production of antimicrobial peptides, such as cathelicidin and defensin $\beta 2$ [91-93]. Indeed, observational evidence suggests that vitamin D deficiency may be involved in the pathophysiology of various infectious diseases [81,94-96].

On the other hand, calcitriol reduces macrophage surface expression of MHC class II molecules, resulting in reduced macrophage antigen presentation ability and T-cell stimulatory capacity $[88,97]$. Calcitriol favours the shift of macrophage polarization from M1 phenotype (proinflammatory phenotype) towards M2 phenotype (anti-inflammatory phenotype) [98], resulting in the up-regulation of IL-10 and downregulation of inflammatory stimuli (e.g., IL-1 $\beta$, IL-6, TNF- $\alpha$, RANKL, 
COX-2) [82,99]. Calcitriol also modulates the morphology, differentiation and function of DCs, rendering them more adherent spindle-shaped, less mature and more tolerogenic, thereby reducing their antigen presentation ability [82]. In DCs, calcitriol has been shown to downregulate IL- 6 and IL-12, upregulate IL-10, and decrease the expression of MHC class II molecules and co-stimulatory molecules CD80 and CD86 [100]. With regard to vitamin D effects on adaptive immune system, it has been shown that calcitriol: i) inhibits the production of Th1 cytokines (e.g., IL2, IFN- $\gamma$ ), Th9 cytokines (e.g., IL-9) and Th17 cytokines (e.g., IL-17, IL21) $[81,82,101]$, ii) upregulates Th2 cytokines (e.g., IL-4, IL-5) [82], iii) induces IL-10-producing Tregs [82,101], and iv) affects Th cell balance by increasing Th 2 cells and inhibiting Th1 and Th17 cell differentiation, thus leading to a shift of $\mathrm{T}$ cells from an effector (pro-inflammatory) phenotype towards a regulatory (anti-inflammatory) phenotype $[74,82,102,103]$. A direct effect of calcitriol on CD8 + T cell hyperactivation has also been reported and consists in the calcitriol ability to reduce the secretion of IFN- $\gamma$ and TNF- $\alpha$ and increase the synthesis of anti-inflammatory cytokines IL- 5 and transforming growth factor beta (TGF- $\beta$ ) by these cells [104]. Notably, the effects of calcitriol on T cells are mediated by both direct actions and indirect actions on innate immune cells, such as DCs [82]. In human T cells, T-cell antigen receptor (TCR) signaling via p38 leads to subsequent induction of VDR and phospholipase C-gamma 1 (PLC- $\gamma 1$ ), which are required steps for classical TCR signaling and T-cell activation [105]. In another study conducted on human $\mathrm{T}$ cells, calcitriol was able to promote the differentiation of Tregs, inhibit Th17 cell proliferation, suppress IL-17 production and significantly upregulate PLC- $\gamma 1$ expression, which then induced the expression of the anti-inflammatory cytokine TGF- $\beta 1$ [106]. These results suggest that calcitriol indirectly modulates the differentiation of human Treg/Th17 cells by affecting the VDR/PLC- $\gamma 1 /$ TGF- $\beta 1$ pathway. Finally, calcitriol has been shown to exert a direct effect on $B$ cells by inhibiting the generation of plasma cells and post-switch memory B cells, thus inhibiting the proliferation of activated B cells and inducing their apoptosis [90].

\section{Role of vitamin $D$ in autoimmune diabetes: T1D and LADA}

Over the last years, vitamin D deficiency has been increasingly suggested as a risk factor for several autoimmune diseases [74,107-111], including T1D [112-115]. Several studies showed that incidence of T1D is directly correlated with latitude and inversely correlated with ultraviolet radiation [116-120]. A number of observational studies showed that subjects with new-onset and established T1D exhibited significantly lower levels of 25(OH)D compared to healthy controls [121-130]. Other studies documented the existence of a significant seasonality in the incidence of T1D, consisting of a higher percentage of incident cases observed during winter, early spring and late autumn compared to late spring and summer months $[131,132]$.

Since vitamin D deficiency is highly prevalent in autoimmune diseases, several studies have also investigated the therapeutic value of vitamin D supplementation in such diseases, including T1D [111]. It has been suggested that higher serum vitamin D levels and vitamin D intake during infancy and early childhood may have a role in reducing the risk of T1D later in life $[112,133,134]$. Moreover, pre-clinical evidence suggests a potential role of vitamin $\mathrm{D}$ in the regulation of beta-cell function and insulin synthesis and secretion [112,135]. Indeed, human pancreatic beta cells express both $1 \alpha$-hydroxylase [136-138] and VDR [139], and a vitamin D response element (VDRE) has been found in the human insulin gene promoter [140]. In addition, vitamin D has been found to be capable of promoting beta-cell survival through a VDRdependent transcriptional program enhancing anti-inflammatory responses [141]. A number of studies conducted in non-obese diabetic (NOD) mice (an animal model of T1D) demonstrated that calcitriol and its analogs can prevent or halt the progression of autoimmune diabetes and insulitis [112]. Moreover, transgenic mice overexpressing VDR in beta cells are protected against streptozotocin-induced diabetes and exhibit preserved beta-cell mass, along with reduced islet inflammation [142]. Interestingly, a recent study [143] showed that DBP is highly expressed in murine and human alpha cells, and loss of DBP gives rise to alterations in alpha-cell number and size, electrical activity and glucagon secretion in vitro and in vivo. Additionally, authors found reduced expression levels of DBP in islets of donors with late-onset or long-standing T1D [143].

Studies conducted in subjects with T1D suggest that vitamin D can exert direct effects on T cells. Gabbay et al. [61] showed that vitamin $\mathrm{D}_{3}$ administration in patients with new-onset T1D (at a dose of $2000 \mathrm{IU} /$ day and in addition to insulin therapy) led to a significant increase in the percentage of Tregs at 12 months compared to placebo. Thereafter, Treiber et al. [144] showed that vitamin $\mathrm{D}_{3}$ supplementation for 12 months in patients with new-onset T1D (at a dose of $70 \mathrm{IU} / \mathrm{kg}$ body weight/day) was associated with a significant improvement in Treg suppressor capacity compared to placebo. In a study conducted in 12 children positive for islet autoantibodies, calcitriol administration (at a dose of $0.25 \mu \mathrm{g}$ /day) led to negativization of GADA and IAA after a median time of 6 months [145].

However, intervention studies and randomized controlled trials investigating the efficacy of vitamin D as an adjuvant immunomodulatory agent aimed to preserve residual beta-cell function and improve glucose control in recent-onset T1D have yielded inconclusive results [112]. Several reasons may underlie the discrepancies in results observed across these studies, including the heterogeneity of study duration, vitamin D formulations (e.g., cholecalciferol, calcifediol, calcitriol, alfacalcidol) and vitamin D doses, timing and schedule of administration [112]. Thus, the heterogeneous study design across the studies limits, at least in part, the interpretation of these results. Moreover, most studies only assessed fasting C-peptide level as a marker of residual beta-cell function, without evaluating stimulated C-peptide. In addition, clinical outcomes were mostly evaluated solely in relation to the administered vitamin D dose, whereas serum 25(OH)D levels at baseline and/or during follow-up were not reported. Indeed, individual serum response to a given vitamin $\mathrm{D}$ dose is markedly variable and depends upon multiple factors, such as baseline vitamin D status, body fat percentage, seasonal variations, ethnicity, genetics (e.g., gene polymorphisms), use of certain medications and different types of vitamin D formulations [146,147]. This aspect is particularly relevant in the setting of autoimmune diseases. In fact, immunomodulatory effects of vitamin D may be achieved in vivo upon attainment of serum 25(OH)D concentrations above those required for bone health (e.g., $40-60 \mathrm{ng} / \mathrm{mL}$ vs. $30-40 \mathrm{ng} / \mathrm{mL}$, respectively). It is also worth noting that achievement of serum $25(\mathrm{OH}) \mathrm{D}$ levels $\geq 40 \mathrm{ng} / \mathrm{mL}$ after vitamin $\mathrm{D}_{3}$ supplementation (at a dose of up to 10,000 IU/day) has proven to be safe over a shortterm period in otherwise healthy vitamin D-deficient subjects [148]. High dose vitamin D supplementation has also proven to be safe in longterm hospitalized patients [149]. Interestingly, a small study investigated the immunomodulatory effects of calcifediol administered for 12 months in children with new-onset T1D [150]. The study was designed to achieve and maintain serum 25(OH)D levels above $50 \mathrm{ng} / \mathrm{mL}$ during the follow-up period. Target serum 25(OH)D levels were safely reached and maintained. Peripheral blood mononuclear cell (PBMC) reactivity against GAD-65 and proinsulin decreased significantly upon $25(\mathrm{OH}) \mathrm{D}_{3}$ replenishment, and this reduction was inversely correlated with serum 25(OH)D concentrations. Fasting C-peptide levels remained stable after one year of calcifediol administration [150].

On the other hand, only a few studies have investigated the role of vitamin D in LADA. Du et al. [151] found a higher surface expression of CD14 and Toll-like receptor 4 (TLR4) on monocytes collected from LADA patients, as compared to controls. The authors showed that calcitriol was able to modulate the increase in IL- $1 \beta$ and TNF- $\alpha$ production by monocytes in response to lipoteichoic acid and lipopolysaccharide [151]. A Swedish case-control study found that $\geq 1$ serving per week consumption of fatty fish (a food source containing high amounts of vitamin D) may reduce the risk of LADA [152]. With regard to 
intervention studies, Li et al. [68] showed that 12-month treatment with the vitamin D analog alfacalcidol (at a dose of $0.5 \mu \mathrm{g} /$ day) in addition to insulin therapy resulted in a partial preservation of beta-cell function in patients with LADA. Notably, authors showed steady fasting and stimulated C-peptide levels in the alfacalcidol plus insulin group, whereas fasting C-peptide levels decreased in the insulin alone group during the 12-month intervention period. Moreover, LADA patients with a shorter duration of the disease ( $<1$ year) exhibited a better response to alfacalcidol in terms of preservation of fasting- and stimulated C-peptide levels, as compared to patients who received insulin therapy alone [68]. Therefore, future prospective intervention studies investigating the efficacy of vitamin D supplementation as an adjuvant immunomodulatory strategy in patients with T1D and LADA are warranted.

\section{DPP-4 and immune system}

Dipeptidyl peptidase-4 (DPP-4) - a serine exopeptidase also known as cluster of differentiation 26 (CD26) - is a cell surface antigen (DPP-4/ CD26) expressed ubiquitously in several cells and tissues including kidney, intestine, liver, lung, endothelia, pancreatic duct and islet cells, as well as in immune cells such as DCs, monocytes, macrophages, T cells, activated B cells and activated natural killer (NK) cells [153-155]. DPP4/CD26 is a type II transmembrane, homodimeric glycoprotein anchored to the membrane by its signal peptide. However, CD26/DPP4 also exists in a soluble form, which still maintains its enzymatic activity and is thought to be released from the cell membrane into the bloodstream [153].

Upon activation, approximately $50 \%$ of human B cells express DPP4/CD26, and selective suppression of DPP-4 activity reduces B-cell activation and DNA synthesis in a dose-dependent manner [153]. DPP4/CD26 plays important co-stimulatory T-cell functions: it is expressed only on a fraction of resting $\mathrm{T}$ cells, whereas it becomes markedly upregulated upon T-cell activation [153]. As a lymphocyte cell surface protein, CD26 has three main functions, all of which can affect T-cell proliferation and chemotaxis, namely: (a) adenosine deaminase (ADA) binding, (b) peptidase activity, and (c) extracellular matrix binding [156].

Interaction of ADA-CD26 complexes on T-cell surface induces costimulatory effects on T-cell activation which are independent of dipeptidyl peptidase and deaminase activities [157]. This costimulatory signal results in a marked increase in the production of Th1 and pro-immflamatory cytokines IFN- $\gamma$, TNF- $\alpha$ and IL-6 [157]. Also, it has been demonstrated that caveolin-1 is a co-stimulatory ligand for CD26, and caveolin-1/CD26 interaction induces T-cell proliferation and nuclear factor kappa B (NF-kB) activation with subsequent costimulation of TCR/CD3 [158]. With regard to CD8+ T cells, CD26mediated co-stimulation of CD8 $+\mathrm{T}$ cells appears to exert a cytotoxic effect mainly via granzyme B, TNF- $\alpha$, IFN- $\gamma$ and Fas ligand [159]. Moreover, CD26-costimulation pathways in CD8+ CD26 $6^{\text {high }} \mathrm{T}$ lymphocytes are mediated by EGR2 (early growth response 2 ) and IL-10, and are therefore distinct from those of CD8 + CD28 ${ }^{\text {high }} \mathrm{T}$ cells [160].

In addition, it has been shown that DPP-4/CD26 is a negative selection marker for human Tregs [161,162], while human Th17 cells exhibit high levels of enzymatically active DPP-4/CD26 [163]. Phenotypic analysis of human CD4+ T cells conducted by Bengsch et al. [163] showed that CD26 expression is highest on Th17 cells producing type 17 cytokines (e.g., IL-22, IL-17, TNF) compared to Th1, Th2, and Tregs. In particular, the lowest CD26 expression levels identified for IL-10producing $\mathrm{CD} 4+\mathrm{T}$ cells and $\mathrm{CD} 25^{\text {hi }} \mathrm{CD} 127^{-} \mathrm{FOXP}^{+}{ }^{+}$regulatory $\mathrm{T}$ cells suggest suppressive effects exerted by CD26 on these cells [163]. Similar findings have recently been observed by Zhao et al. [164], who investigated the role of CD26 in T-cell differentiation in vitro by analyzing CD26 expression in different subsets of human peripheral blood $\mathrm{T}$ cells after solid-phase immobilized specific monoclonal anti-CD3 antibody stimulation. Authors found that the percentages of cells secreting Th1 cytokines (IL-2 and IFN- $\gamma$ ) and Th17 cytokines (IL-6, IL-17, and IL-22) or expressing Th17 typical biomarkers (CD161, CD196, and IL-23 receptor) in the CD26 high group were substantially higher compared to the CD26 ${ }^{\text {low }}$ group. Furthermore, fluorescence microscopy revealed a coexpression of CD26 with IL-2, IFN- $\gamma$, IL-17, IL-22, and IL-23R in lymphocytes [164]. These findings provide evidence that the high expression of CD26 is accompanied by the differentiation of T cells into Th1 and Th17 subsets, further indicating that $\mathrm{CD} 26$ plays a pivotal role in the regulation of immune responses.

CD26 binds to caveolin-1 on APCs and upregulates the costimulatory molecule CD86, resulting in the engagement with CD28 on $\mathrm{T}$ cells and subsequent antigen-specific $\mathrm{T}$ cell activation [165]. CD26 also acts as a binding protein for ADA, anchoring it to the cell surface and reducing the local concentrations of adenosine [166]. ADA is an enzyme which downregulates the biologic effects of adenosine in situ by catabolizing adenosine to its metabolite inosine. The surface-aligned CD26/ADA complex deaminates adenosine and prevents its binding to the adenosine receptor A2A on immune cells. As a result, effector T cells can escape from adenosine-mediated suppression, thus promoting inflammation [167]. Thus, blockade of surface-bound ADA activity favours exogenous adenosine access to A2A receptors on effector T cells and promotes adenosine-mediated suppression in these cells. As previously mentioned, CD26 expression is absent or negligible in Tregs; hence, Tregs cannot efficiently anchor ADA to their membranes, leading to reduced ADA activity and subsequent extracellular adenosine accumulation which ultimately results in suppressive effects on effector $\mathrm{T}$ cells.

In keeping with the aforementioned findings, our group previously demonstrated that the DPP-4 inhibitor sitagliptin exerts immunomodulatory properties in human lymphocytes through several mechanisms, including: i) dose-dependent inhibition of PBMC proliferation and decreased PBMC CD26 expression; ii) decreased production of IL- 6 and IFN- $\gamma$; iii) reduction in the percentage of $\mathrm{CD}^{+} / \mathrm{IL}-17^{+}$and $\mathrm{CD} 4^{+} / \mathrm{IFN}-\gamma^{+}$ $\mathrm{T}$ cells, and iv) increase in TGF- $\beta 1$ concentrations [168]. Altogether, these findings suggest DPP-4 inhibition as a valuable therapeutic option in chronic inflammatory and autoimmune diseases.

\section{Role of DPP-4 inhibitors in autoimmune diabetes: T1D and LADA}

DPP-4 substrates are polypeptides with an alanine or a proline at the second position from the N-terminal side. DPP-4 cleaves off aminoterminal dipeptides from several substrate hormones, neuropeptides, chemokines and growth factors, thus influencing the biological activity of such molecules [153]. In this regard, DPP-4 was identified as a therapeutic target in T2D due its ability to cleave and inactivate the gut hormones (incretins) known as gastric inhibitory polypeptide (GIP, also referred to as glucose-dependent insulinotropic polypeptide) and glucagon-like peptide-1 (GLP-1), which are secreted by enteroendocrine $\mathrm{K}$ and L cells, respectively [153]. GIP and GLP-1 are secreted from gut enteroendocrine cells upon meal ingestion and promote insulin secretion in a glucose-dependent manner $[169,170]$. DPP-4 inhibition blocks incretin degradation and increase endogenous levels of incretins by prolonging their half-life, thus extending the insulinotropic effect of such hormones, lowering fasting and postprandial glucose concentration, suppressing glucagon secretion and reducing hepatic glucose production $[171,172]$. Recently, it has also been shown that DPP-4 inhibition can modulate insulin secretion via GLP-1-independent mechanisms, such as the regulation of intra-islet peptide YY (PYY) [173].

DPP-4 inhibitors (DPP-4i), also known as gliptins, have proven to be effective in enhancing endogenous insulin secretion and impoving glucose control in patients with T2D [172]. Since 2006, several DPP-4i have become available as oral antihyperglycemic agents for the treatment of T2D, including sitagliptin, vildagliptin, linagliptin, saxagliptin and alogliptin [172]. Pre-clinical evidence and experimental studies also suggest that DPP-4i can exert pleiotropic effects beyond their glucose- 
lowering properties, conferring protection against cardiovascular disease and microvascular diabetes-related complications through both GLP-1-dependent and GLP-1-independent mechanisms [174,175]. In addition, several studies suggest that DPP-4i exert anti-inflammatory and immunomodulatory effects in vitro and in vivo [176-181]. In short-term randomized controlled trials conducted in patients with T2D, sitagliptin has been shown to increase the expression of IL-10 (an antiinflammatory cytokine) and to reduce the expression of different markers of low-grade inflammation, pro-inflammatory cytokines and cell adhesion molecules, such as C-reactive protein, IL-6, IL-18, TNF- $\alpha$, secreted phospholipase-A2, serum amyloid A-LDL complex, soluble intercellular adhesion molecule-1 (sICAM-1) and E-selectin $[176,177,181]$. These effects may provide a further advantage in the prevention and management of diabetes-related proatherogenic comorbidities. Furthermore, a recent large retrospective cohort study involving more than 750,000 patients with T2D found that DPP-4i are associated with lower risk of autoimmune disorders, particularly for the younger patients and the lesser duration of diabetes diagnosed [182].

Given their anti-inflammatory/immunomodulatory properties and their ability to increase circulating levels of incretins, DPP-4i have the potential to exert multiple positive effects on pancreatic beta cells leading to the preservation of beta-cell mass and function, namely: i) improvement of glucose-stimulated insulin secretion (GSIS); ii) reduction of gluco-, lipo- and cytokine-toxicity; iii) stimulation of insulin gene expression and biosynthesis; iv) suppression of beta-cell apoptosis; and v) stimulation of beta-cell proliferation, survival and neogenesis from endocrine progenitor cells within islet and extra-islet pancreas tissue, as it has been demonstrated in animal models of diabetes and isolated human islets [176,178,183-188].

Therefore, the use of DPP-4i has been suggested as a valid treatment option in patients with autoimmune diabetes [189]. Animal studies conducted in NOD mice showed that DPP-4i were able to prevent or delay the onset of diabetes and even reverse the established disease after the onset of overt hyperglycemia by modulating the inflammatory and autoimmune responses against pancreatic beta cells and thereby protecting beta-cell mass [190-194]. In such animal models of autoimmune diabetes, DPP-4i: i) reduce insulitis, ii) stimulate beta-cell proliferation, iii) increase $\mathrm{CD} 4+\mathrm{CD} 25+\mathrm{FOXP} 3+$ regulatory $\mathrm{T}$ cells, and iv) reduce migration of splenic and lymph node CD4+ T-cells [190-194]. A recent animal study conducted in a streptozotocin-induced T1D experimental model demonstrated that treatment with sitagliptin was able to improve metabolic control, decrease pancreatic inflammatory profile and increase systemic regulatory T cell frequency [195].

Case reports and small pilot studies conducted in patients with autoimmune diabetes have found that DPP-4i, alone or in combination with other agents, significantly improved glucose control and reduced insulin requirements, with a favourable tolerability profile [189]. However, studies investigating the use of DPP-4i in T1D led to inconclusive results in terms of improvement of glucose control, reduction of daily insulin requirements, as well as preservation or increase of endogenous insulin production [189,196-199]. The inconsistent findings observed across studies may be explained by a number of factors, such as the small sample size and the heterogeneous diabetes duration at enrollment. For instance, the inclusion of T1D subjects with longstanding disease and only marginal residual beta-cell function may reduce the potential benefits of DPP-4 inhibition in this population. The 12-month randomized, placebo-controlled, phase 2 trial REPAIR-T1D showed lack of efficacy of combination therapy with sitagliptin plus the proton-pump inhibitor lansoprazole in preserving beta-cell function in patients with new-onset T1D [200]. These findings differ from those observed in NOD mice [201]. However, the use of a lower sitagliptin dose ( $50 \mathrm{mg}$ /day) in patients younger than 18 years may have not been adequate to achieve the in vivo anti-inflammatory effects of sitagliptin. It is also worth noting that serum DPP-4 activity is higher in both children and adults with T1D compared to healthy controls [202-205] and subjects with T2D [205]. Duvnjak et al. [206] showed that LADA patients exhibited a significantly higher serum DPP-4 activity compared to subjects with T1D and T2D. In the multinomial regression analysis, DPP-4 activity remained significantly associated with both LADA and T1D, whereas it did not show an association with T2D [206]. Interestingly, it has also been suggested that increased DPP-4 activity mediates the impairment in insulin sensitivity driven by TNF- $\alpha$ in T1D [207]. Additionally, patients with T1D using bolus rapid-acting insulin analogues exhibit lower postprandial GLP-1 levels following ingestion of test meal [208]. Altogether, these findings may partly explain the inability of several participants to achieve adequate GLP-1 levels in the REPAIRT1D study [200]. In fact, authors found a slight trend towards C-peptide preservation in a subgroup who produced increased concentrations of GLP-1 and gastrin while receiving the treatment [200]. These findings appear to suggest that the dose of DPP-4i administered in clinical studies may significantly affect the study outcomes. In this regard, our group previously showed that sitagliptin-mediated inhibition of human PBMC proliferation is dose-dependent [168]. Of note, sitagliptin was able to modulate the differentiation of Th1 and Th17 cells into TGF- $\beta 1$-producing regulatory cells and to markedly reduce the expression of IFN- $\gamma$, IL-6 and IL-17 [168]. Similar findings have also been observed in animal models of diabetes $[194,209]$. Thus, future studies investigating the role of DPP-4i in preserving beta-cell mass and function in new-onset T1D should consider the administered dose and the disease duration as factors able to significantly affect the study outcomes. Moreover, assessing serum DPP-4 activity and CD26 expression on lymphocytes may be useful in the attempt to establish a minimum DPP-4i dose able to effectively inhibit DPP-4 activity, increase GLP-1 levels and subsequently modulate innate and adaptive immune responses in vivo. It would also be worth taking into account potential differences existing between distinct DPP-4i molecules in terms of pharmacokinetics and anti-inflammatory/immunomodulatory actions. Although it has been demonstrated that different DPP-4i have a similar safety and efficacy profile as oral antihyperglycemic agents for the treatment of T2D [210], the existence of differential effects on immune system exerted by distinct DPP-4i cannot be excluded due to the peculiarity of each molecule in terms of pharmacokinetic and pharmacodynamic characteristics, binding modes of DPP4i in the active site of DPP-4 and ability to interfere with CD26 dimerization [211,212]. The use of DPP-4i as an adjuvant therapeutic strategy to preserve beta-cell function has also been investigated in patients with LADA. An open-label, randomized controlled study first showed that 12-month treatment with sitagliptin (at a dose of $100 \mathrm{mg}$ /day) in addition to insulin preserved C-peptide secretion better than insulin alone in patients with recent-onset LADA (duration of diabetes $\leq 3$ years) [213]. Another open-label, prospective, randomized controlled trial conducted in patients with LADA in the stage of noninsulin-dependency suggested that sitagliptin (at a dose of $50 \mathrm{mg} /$ day, titrated up to $100 \mathrm{mg} /$ day to achieve the established target for glucose control) may be more effective in preserving beta-cell function compared to insulin therapy for at least 4 years [214]. A recent 24month randomized controlled trial conducted in LADA patients (with a disease duration of $\leq 3$ years) demonstrated that sitagliptin (at a dose of $100 \mathrm{mg} /$ day) in addition to insulin led to significantly higher changes in the updated homeostatic model assessment of beta-cell function (HOMA2-B) from baseline, and significantly improved the first-phase insulin secretion (during the hyperglycemic clamp test) and insulin sensitivity (during the hyperinsulinemic euglycemic clamp test) as compared to insulin intervention alone [215]. A 1-year open-label randomized controlled trial conducted in LADA patients also found that sitagliptin ( $100 \mathrm{mg} /$ day) in addition to insulin ameliorated glucose control and altered the phenotype of $\mathrm{T}$ cells by increasing the percentage of protective Th2 cells and reducing the percentage of pathogenic Th17 cells [216]. However, a 21-month randomized trial conducted in LADA patients with $<3$ years of known diabetes found that sitagliptin (at a dose of $100 \mathrm{mg}$ /day) did not lead to significant differences in beta-cell function as compared to insulin therapy [217]. An exploratory analysis of a 2-year double-blind, randomized controlled study conducted in 
patients diagnosed with T2D and HbA1c values of $6.5 \%-10 \%$ while on metformin (who were randomized to additional once-daily linagliptin 5 $\mathrm{mg}$ or glimepiride $1-4 \mathrm{mg}$ ) suggested that linagliptin may attenuate the rate of decline in C-peptide levels among patients with LADA [69]. A post hoc analysis of data pooled from five randomized, placebocontrolled studies found that saxagliptin was effective in reducing blood glucose levels and appeared to improve beta-cell function in GADA-positive patients [218]. In a recent consensus statement from an international expert panel providing recommendations for the management of patients with LADA, DPP-4i have been suggested as oral antihyperglycemic agents able to improve glucose control and potentially preserve residual insulin secretory capacity in this population, although larger randomized studies are warranted to draw definitive conclusions in this direction [29].

\section{VIDPP-4i combination therapy for treatment of autoimmune diabetes}

In light of the aforementioned findings and evidence deriving from studies conducted in other clinical settings [219,220], vitamin D and DPP-4i may exert synergistic effects on immune system by virtue of their anti-inflammatory and immunomodulatory properties. When vitamin D and DPP-4i are administered together, such combination therapy may exert anti-inflammatory and immunomodulatory actions to a greater extent than vitamin D or DPP-4i administered alone. Emerging evidence suggests that combination therapy with vitamin D plus DPP-4i (VIDPP4i) has the potential ability to preserve beta-cell function in autoimmune diabetes [64]. Herein, we discuss the current evidence for the existence of synergistic effects of vitamin D and DPP-4i and the consequential implications for the treatment of autoimmune diabetes.

\subsection{Synergistic anti-inflammatory and immunomodulatory effects of vitamin D and DPP-4 inhibitors: Mechanistic evidence}

Evidence for synergistic anti-inflammatory and immunomodulatory effects of vitamin D and DPP-4i primarily comes from recent studies conducted in patients with T2D. A study conducted by MahabadiAshtiyani et al. [221] on PBMCs collected from T2D patients and healthy controls revealed that the addition to the culture of sitagliptin plus vitamin $\mathrm{D}_{3}$ was more effective in reducing IL- 6 and TNF- $\alpha$ production in both patients and controls, as compared to cultures treated with sitagliptin or vitamin $\mathrm{D}_{3}$ alone. The same group recently demonstrated the in vitro ability of sitagliptin and vitamin $\mathrm{D}_{3}$ to effectively suppress the increased $\mathrm{T}$ helper cell proliferation and inflammatory responses in patients with T2D [222]. Of note, the addition of sitagliptin or vitamin $\mathrm{D}_{3}$ to the cultures led to decreased proliferation of CD4 $+\mathrm{T}$ cells and non-CD4+ cells isolated from both T2D patients and healthy controls. Sitagliptin in combination with vitamin $\mathrm{D}_{3}$ was also more effective in suppressing cell proliferation, decreasing IL-17 production and enhancing the expression of the anti-inflammatory cytokine IL-37 by PBMCs [222].

In a study conducted in 54 nephropathic and 57 non-nephropathic T2D patients, Telikani et al. [223] demonstrated that, as compared to healthy control, the production of IFN- $\gamma$ and IL- 17 was increased and FOXP3 expression was decreased in T2D subjects who did not receive sitagliptin and vitamin $\mathrm{D}_{3}$. On the other hand, VIDPP-4i (vitamin $\mathrm{D}_{3}$ $1000 \mathrm{IU} /$ day plus sitagliptin $100 \mathrm{mg}$ /day) was associated with decreased IFN- $\gamma$, IL-17 and IL-21 production, downregulated expression of ROR $\gamma \mathrm{t}$ (a marker for Th17 cells) and BCL6 (a marker for T follicular helper cells), along with upregulated expression of IL-37 and FOXP3, which are well-known markers for Tregs [223]. Similar results have been observed in another study from the same group, showing that treatment with sitagliptin plus vitamin $\mathrm{D}_{3}$ reduced the levels of IFN- $\gamma$ and IL-17 in both non-nephropathic and nephropathic T2D patients compared to untreated patients [224]. IL-37 levels were enhanced in patients treated with sitagliptin or sitagliptin plus vitamin $\mathrm{D}_{3}$ compared to untreated patients. Moreover, treatment with sitagliptin plus vitamin $\mathrm{D}_{3}$ increased IL-4 levels in non-nephropathic T2D patients. Overall, these findings suggest that treatment with sitagliptin plus vitamin $\mathrm{D}_{3}$ is more effective in reducing the upregulation of the pro-inflammatory cytokines IFN- $\gamma$ and IL-17 in patients with T2D [224]. According to the synergistic anti-inflammatory actions of vitamin D and DPP-4i, a recent study conducted in a rat model of fructose/salt-induced insulin resistance showed superadditive renoprotective effects evoked by the combined use of vitamin $\mathrm{D}_{3}$ and vildagliptin, which reversed hyperuricemia and exerted a plethora of renal anti-inflammatory, antioxidant, anti-apoptotic and anti-fibrotic effects [225].

Interestingly, studies conducted in transplant setting shed light on the rationale for combined use of vitamin D and DPP-4i. Vitamin D deficiency is highly prevalent following solid organ transplantation [226]. Pre-clinical studies showed that vitamin D and its analogs have beneficial effects in terms of islet graft survival and prevention of allograft rejection and recurrence of autoimmunity in animal models of syngeneic and allogeneic islet transplantation [227]. Therefore, vitamin D supplementation has been suggested as a valid therapeutic strategy to reduce opportunistic infections and prevent allograft rejection after solid organ and cell transplantation [226,227]. In this regard, Zhou et al. [228] found that vitamin D deficiency represents an independent risk factor for acute cellular rejection after liver transplantation. Accordingly, the incidence of acute cellular rejection and bacterial and fungal infections was reduced in patients receiving vitamin D supplementation. Moreover, vitamin D supplementation was associated with increased numbers of Tregs and decreased numbers of $\mathrm{T}$ naïve cells and CD8+ CD28+ T cells, suggesting that vitamin D may favour immune tolerance towards the liver allografts [228].

Likewise, DPP-4 inhibition before and after islet transplantation decreased the effect of beta-cell autoimmunity and led to prolongation of islet graft survival in NOD mice, partially by reducing the homing of CD4+ T-cells into pancreatic beta cells [191]. DPP-4 inhibition has recently been suggested as a potential strategy to prevent chronic allograft dysfunction following solid organ transplantation (such as lung transplantation) by inducing an anti-inflammatory cytokine profile [229]. Also, a recent study demonstrated that treatment with a murine anti-CD26 monoclonal antibody (begelomab) induced over $60 \%$ responses in steroid refractory acute graft-versus-host disease (SRaGVHD), thus suggesting a role of CD26 + T cells in tissue damage in the context of GVHD [230]. Accordingly, a recent phase 2 clinical trial showed that sitagliptin (administered orally at a dose of $600 \mathrm{mg}$ every $12 \mathrm{~h}$ starting the day before transplantation until day 14 after transplantation) in addition to a standard immunosuppressive regimen of sirolimus and tacrolimus resulted in a markedly low incidence of grade II to IV acute GVHD by day 100 after myeloablative allogeneic hematopoietic stem-cell transplantation [231,232].

Overall, these findings suggest that the combined use of vitamin D and DPP-4 inhibition (through the use of gliptins or anti-CD26 monoclonal antibodies) may represent a valuable therapeutic option worth being investigated in future studies involving transplant recipients. In fact, VIDPP-4i may modulate T-cell differentiation and promote immune tolerance by selectively inhibiting effector $\mathrm{T}$ cells and upregulating Tregs, potentially allowing for reduction of immunosuppressant dose and immunosuppression-related toxicity. In this context, the use of DPP$4 \mathrm{i}$ may also be advantageous in terms of reduced glucotoxicity and preservation of beta-cell function among patients with T1D who underwent kidney, pancreas or islet transplantation, and patients with post-transplant diabetes [233].

Finally, current mechanistic evidence suggests that vitamin D and DPP-4i exert synergistic anti-inflammatory and immunomodulatory effects on immune system via shared signaling pathways, which result in: i) reduced antigen presentation ability and T-cell stimulatory capacity by APCs; ii) reduced differentiation and activation of Th1 and Th17 cells; iii) enhanced differentiation of Th2 cells and Tregs; iv) reduced differentiation of CD8 $+\mathrm{T}$ cells; v) decreased expression of pro- 
inflammatory cytokines, such as IFN- $\gamma$, TNF- $\alpha$, IL-6 and IL-17; vi) increased expression of anti-inflammatory cytokines, such as TGF- $\beta 1$, IL4, IL-5, and IL-37; vii) decreased activation of B cells and reduced islet autoantibody titres. Fig. 1 illustrates the mechanisms underlying the synergistic anti-inflammatory and immunomodulatory effects exerted by vitamin D and DPP-4i, as well as their protective effects on pancreatic islets and beta cells.

\subsection{VIDPP-4i as an immunomodulation therapy for autoimmune diabetes: Clinical evidence}

Case reports and pilot studies conducted in patients with autoimmune diabetes showed potential protective effects of VIDPP-4i on betacell function (Table 1). We first reported a markedly prolonged clinical remission phase (up to 4 years), accompanied by decreased GADA titres and preserved beta-cell function in two T1D patients who received VIDPP-4i with sitagliptin $100 \mathrm{mg} /$ day plus vitamin $\mathrm{D}_{3} 5000 \mathrm{IU} /$ day
[59]. In a subsequent study involving a larger sample size $(\mathrm{n}=34 ; 17$ T1D patients and 17 controls), we showed that the same VIDPP-4i regimen in addition to insulin therapy was associated with a prolonged clinical remission phase (from 1 to 5 years; mean: $27.1 \pm 18.9$ months), accompanied by a significant reduction in CD8 + CD26+ T cell count compared to T1D patients treated with insulin alone $[64,234]$. In a study conducted on a cohort of 19 patients with new-onset T1D, we recently showed that this combination therapy was associated with residual beta-cell function and a median remission phase (as assessed by an IDAA1c value of $\leq 9$ ) of 10 months (ranging from 6 to 87 months) [65].

Similar findings have been observed in patients with LADA. Of note, Rapti et al. [67] first reported the case of a 31-year-old patient with LADA who received VIDPP-4i with sitagliptin $100 \mathrm{mg}$ /day plus vitamin $\mathrm{D}_{3} 2000 \mathrm{IU} /$ day (in addition to metformin) shortly after the onset of the disease. The patient maintained insulin independence and exhibited normalization of GADA titre levels and HbA1c values over a 2-year

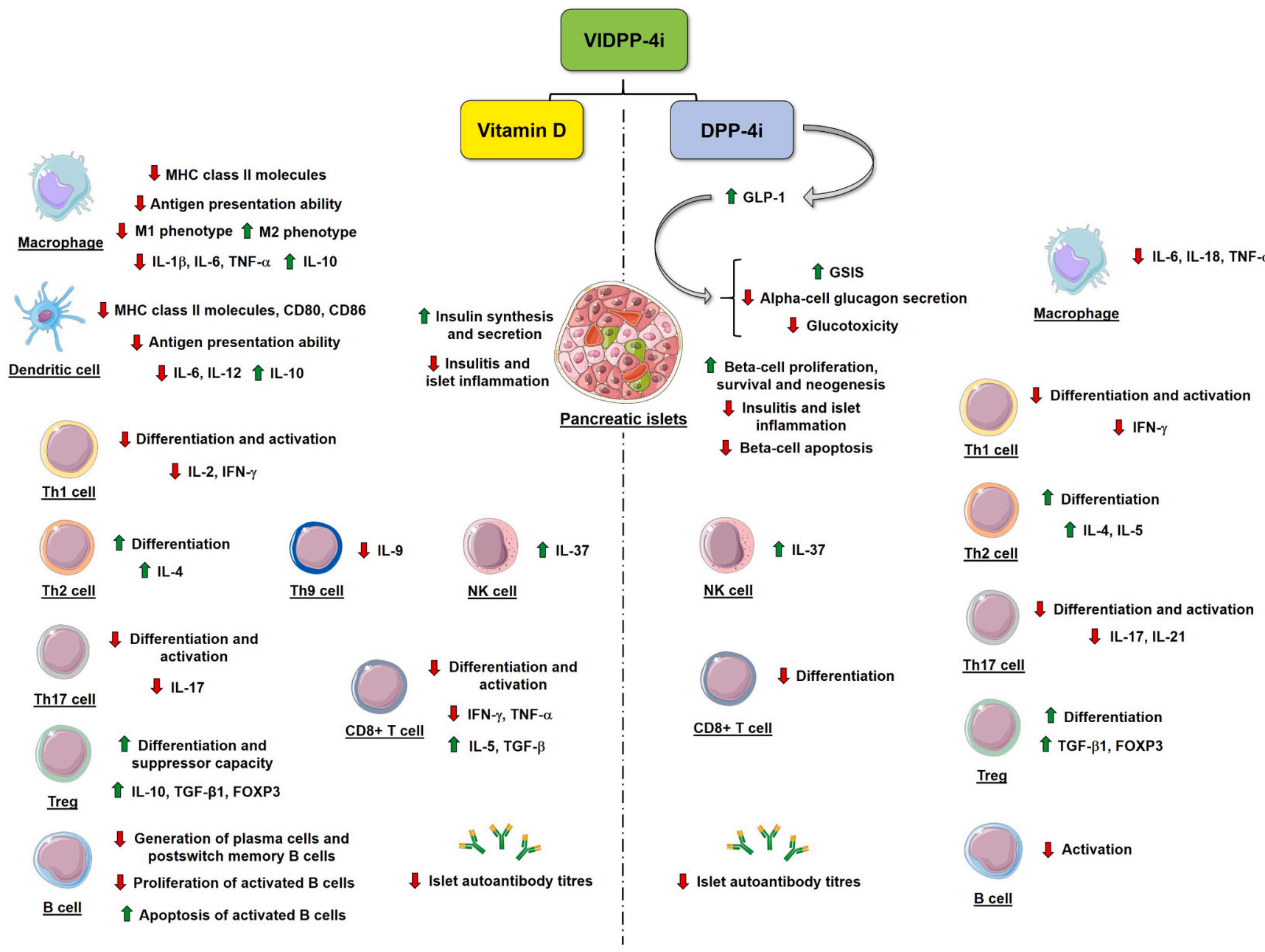

Fig. 1. Mechanisms underlying the synergistic anti-inflammatory and immunomodulatory effects of vitamin D and DPP-4 inhibitors in autoimmune diabetes. Studies conducted in vitro and in animal models of autoimmune diabetes showed that vitamin D and DPP-4 inhibitors promote the activation of antiinflammatory and immunomodulatory pathways, resulting in protective effects on pancreatic islets and beta cells. Notably, vitamin D and DPP-4 inhibitors (VIDPP-4i) exert synergistic effects on innate and adaptive immune system via shared signaling pathways, which primarily result in: i) reduced antigen presentation ability and T-cell stimulatory capacity by antigen-presenting cells; ii) reduced differentiation and activation of Th1 and Th17 cells; iii) enhanced differentiation of Th2 cells and Tregs; iv) reduced differentiation of CD8+ T cells; v) decreased expression of pro-inflammatory cytokines, such as IFN- $\gamma$, TNF- $\alpha$, IL-6, IL-17; vi) increased expression of anti-inflammatory cytokines, such as TGF- $\beta 1$, IL-4, IL-5, and IL-37; vii) decreased activation of B cells and reduced islet autoantibody titres. In addition, DPP-4 inhibitors exert well-known GLP-1-mediated protective effects on beta cells, by promoting glucose-stimulated insulin secretion, suppressing glucagon secretion and reducing glucotoxicity. The term vitamin D refers to the active metabolite calcitriol. Abbreviations: DPP-4i, dipeptidyl peptidase-4 inhibitors; GLP-1, glucagon-like peptide-1; GSIS, glucose-stimulated insulin secretion; IFN- $\gamma$, interferon-gamma; IL, interleukin; MHC, major histocompatibility complex; NK cell, natural killer cell; TGF- $\beta 1$, transforming growth factor beta 1 ; Th, T helper cell; TNF- $\alpha$, tumor necrosis factor-alpha; Treg, regulatory T cell; VIDPP-4i: combination therapy with vitamin D and DPP-4 inhibitors. 
Table 1

Summary of the main studies on the use of combination therapy with vitamin D and DPP-4 inhibitors (VIDPP-4i) in patients with autoimmune diabetes (T1D and LADA)

\begin{tabular}{|c|c|c|c|c|}
\hline Study Design & Study Population & Study Treatment & Main Findings & References \\
\hline Case series & $\begin{array}{l}\mathrm{N}=2 \text { young adults with T1D } \\
\text { Patient \#1: } 20 \text {-year-old woman } \\
\text { Patient \#2: } 21 \text {-year-old woman } \\
\text { T1D duration at VIDPP-4i initiation: } \\
\text { patient\#1, } 1 \text { month; } \\
\text { patient \#2, } 10 \text { months. }\end{array}$ & $\begin{array}{l}\text { Sitagliptin } 100 \mathrm{mg} / \text { day plus vitamin } \mathrm{D}_{3} 5000 \mathrm{IU} / \text { day, with or without } \\
\text { insulin }\end{array}$ & $\begin{array}{l}\text { Both patients experienced clinical remission of T1D, as evidenced by a } \\
\text { daily insulin requirement of }<0.5 \mathrm{IU} / \mathrm{kg} / \mathrm{day} \text {, HbA1c values below } 6 \% \\
\text { and fasting C-peptide levels above } 0.90 \mathrm{ng} / \mathrm{mL} \text {. Both patients showed } \\
\text { an early and significant decrease in GADA titres, which remained } \\
\text { below the baseline levels } \\
\text { throughout a } 48 \text {-month follow-up period. } \\
\text { Patient \#1: complete clinical remission (without need for insulin } \\
\text { therapy) maintained during a 4-year follow-up period. } \\
\text { Patient \#2: partial clinical remission maintained during a 4-year } \\
\text { follow-up period. } \\
\text { Both patients maintained normal serum levels of } \\
\text { calcium and } 25(\mathrm{OH}) \text { D. No side effects related to } \\
\text { VIDPP-4i have been reported. }\end{array}$ & $\begin{array}{l}\text { Pinheiro et al. (2016) } \\
\text { [Ref. [59]] }\end{array}$ \\
\hline $\begin{array}{l}\text { Cross-sectional } \\
\text { study }\end{array}$ & $\begin{array}{l}\mathrm{N}=17 \text { children and adults with T1D } \\
\text { (receiving insulin in combination with } \\
\text { sitagliptin and/or vitamin } \mathrm{D}_{3} \text { ) vs. } 17 \\
\text { controls }\end{array}$ & $\begin{array}{l}10 \text { T1D subjects (age range: } 16-43 \text { years, } 7 \mathrm{~F} / 3 \mathrm{M}) \text { were treated with } \\
\text { insulin alone; } 5 \text { T1D subjects (age range: } 20-47 \text { years, } 3 \mathrm{~F} / 2 \mathrm{M} \text { ) were } \\
\text { treated with insulin and sitagliptin } 100 \mathrm{mg} / \text { day plus vitamin } \mathrm{D}_{3} 5000 \\
\text { IU/day; } 2 \text { subjects with new-onset T1D ( } 13 \text { and } 15 \text { years, } 1 \mathrm{~F} / 1 \mathrm{M}) \\
\text { were treated with sitagliptin } 100 \mathrm{mg} / \text { day and vitamin } \mathrm{D}_{3} 5000 \mathrm{IU} / \\
\text { day. } \\
\text { Eight healthy donors (age range: } 19-34 \text { years, } 6 \mathrm{~F} / 2 \mathrm{M} \text { ) and } 9 \text { women } \\
\text { (age range: } 15-39 \text { years) with Hashimoto's thyroiditis served as } \\
\text { control group. }\end{array}$ & $\begin{array}{l}\text { VIDPP- } 4 \text { r regimen in addition to insulin therapy was associated with a } \\
\text { prolonged clinical remission phase (from } 1 \text { to } 5 \text { years; mean } 27.1 \pm \\
18.9 \text { months), accompanied by a significant reduction in CD8+ } \\
\text { CD26+ T cell count compared to T1D patients treated with insulin } \\
\text { alone (p-value }=0.022) . \\
\text { No side effects related to VIDPP-4i were reported. }\end{array}$ & $\begin{array}{l}\text { Pinheiro et al. (2017); } \\
\text { Pinheiro et al. (2018) } \\
\text { [Ref. [234,64]] }\end{array}$ \\
\hline Case series & $\begin{array}{l}\mathrm{N}=19 \text { children and adults }(7 \mathrm{~F} / 12 \mathrm{M} \text {; } \\
\text { median } \\
\text { age } 15 \text { years [6-39]) with new-onset } \\
\text { T1D }\end{array}$ & $\begin{array}{l}\text { Sitagliptin } 100 \mathrm{mg} / \text { day plus vitamin } \mathrm{D}_{3} 5000 \mathrm{IU} / \text { day (in addition to } \\
\text { insulin therapy) }\end{array}$ & $\begin{array}{l}\text { The use of VIDPP- } 4 \mathrm{i} \text { was associated with residual beta-cell function, } \\
\text { along with a median remission phase (as assessed by an IDAA1c value } \\
\text { of } \leq 9 \text { ) of } 10 \text { months (ranging from } 6 \text { to } 87 \text { months). } \\
\text { Mean fasting C-peptide levels at baseline were } 0.86 \pm 0.47 \mathrm{ng} / \mathrm{mL} \text {, } \\
\text { whereas last follow-up mean C-peptide levels were } 0.89 \pm 0.57 \mathrm{ng} / \mathrm{mL} \text {. }\end{array}$ & $\begin{array}{l}\text { Pinheiro et al. (ATTD } \\
2020 \text { Invited Speaker } \\
\text { Abstracts, 2020) [Ref. } \\
\text { [65]] }\end{array}$ \\
\hline Case report & 31-year-old Caucasian male with LADA & $\begin{array}{l}\text { Sitagliptin } 100 \mathrm{mg} \text { /day plus vitamin } \mathrm{D}_{3} 2000 \mathrm{IU} / \text { day administered in } \\
\text { addition to metformin (1700 mg/day) shortly after the onset of the } \\
\text { disease }\end{array}$ & $\begin{array}{l}\text { No side effects related to VIDPP-4i were reported. } \\
2 \text { years after the diagnosis of LADA, the patient showed normalization } \\
\text { of HbA1c values (5.2\% vs } 9.6 \%) \text {, as well as negativization of GADA } \\
\text { titres }(4.1 \mathrm{U} / \mathrm{mL} \text { vs } 32 \mathrm{U} / \mathrm{mL} \text {; normal } \\
\text { values }<5 \mathrm{U} / \mathrm{mL}) \text {. } \\
\text { VIDPP-4i was well tolerated. }\end{array}$ & $\begin{array}{l}\text { Rapti et al. (2016) [Ref. } \\
\text { [67]] } \\
\text { (continued on next page) }\end{array}$ \\
\hline
\end{tabular}


follow-up period [67]. Recently, Zhang et al. [66] conducted a 12-month multicenter, randomized controlled study in 60 LADA patients (disease duration $<4$ years) to explore the protective effects on beta-cell function of VIDPP-4i with vitamin $\mathrm{D}_{3}$ and saxagliptin in addition to conventional therapy with metformin and/or insulin. Participants were randomized to receive: i) conventional therapy with metformin (1-1.7 g/day) and/or insulin treatment; ii) saxagliptin ( $5 \mathrm{mg}$ /day) plus conventional therapy; or iii) vitamin $\mathrm{D}_{3}$ (2000 IU/day) plus saxagliptin and conventional therapy for 12 months. In participants who received VIDPP-4i, levels of fasting C-peptide and fasting C-peptide index (CPI, calculated as the ratio of serum C-peptide to plasma glucose) were not significantly different at 12 months compared to those at baseline, whereas postprandial C-peptide index levels increased (although not significantly) during the follow-up period. However, insulin dose showed no significant differences at 6 and 12 months. On the other hand, postprandial Cpeptide index levels declined significantly at 12 months in participants who received conventional therapy alone. Even more surprisingly, participants who received saxagliptin in addition to conventional therapy without vitamin $\mathrm{D}_{3}$ exhibited significantly decreased fasting Cpeptide levels at 12 months compared to those at baseline [66]. Additionally, patients on VIDPP-4i showed a significant reduction in the GADA titre levels at 12 months compared to those at baseline, whereas no significant changes in GADA titres were reported in the other two groups after 12 months of treatment. VIDPP-4i was safe and well tolerated, with no side effects reported throughout the follow-up period [66]. These findings seem to suggest that saxagliptin alone cannot fully reverse glucotoxicity and/or exert anti-inflammatory and immunomodulatory effects to preserve and maintain beta-cell function in autoimmune diabetes. By contrast, adding vitamin $\mathrm{D}_{3}$ to saxagliptin might have the potential to better protect beta-cell function, as a likely consequence of the synergistic effects exerted by vitamin D and DPP-4i on immune system and inflammatory pathways.

\section{Discussion and conclusion}

Over the last years, several studies showed that vitamin D and DPP-4i can exert pleiotropic actions beyond their well-established role in the regulation of bone and glucose homeostatis, respectively. Emerging preclinical evidence supports the existence of synergistic anti-inflammatory and immunomodulatory properties of vitamin D and DPP-4i, which result in the reduction of pro-inflammatory and autoimmune responses against pancreatic beta cells in animal models of autoimmune diabetes. Preliminary findings also suggest that VIDPP-4i therapy has the potential ability to preserve beta-cell function in patients with autoimmune diabetes, including T1D and LADA.

To date, immunotherapies have mostly showed no effect or only a transient beneficial effect in reducing the decline in beta-cell function that occurs over time in autoimmune diabetes. Therefore, the use of immunotherapeutic agents in a combination therapy appears to be a valid approach to obtain better results in terms of preservation of betacell mass and function. In particular, targeting multiple pathways involved in beta-cell loss and dysfunction (e.g. innate immunity, adaptive immunity, regulatory immunity, glucotoxicity) may represent a successful immune intervention for autoimmune diabetes. In this context, combination therapy with vitamin D and DPP-4i may be an attractive choice in the treatment of T1D, LADA, other forms of autoimmune diabetes or other autoimmune diseases. Indeed, vitamin $\mathrm{D}$ and DPP-4i co-administration may substantially enhance the efficacy of each of these compounds as immunomodulatory agents compared to their use as monotherapy (vitamin D alone or DPP-4i alone). Vitamin D may promote anti-inflammatory responses, exert immunomodulatory effects, induce immune tolerance and potentially stimulate insulin synthesis and secretion. On the other hand, DPP-4i have been shown to exert similar actions on innate and adaptive immune system. Moreover, DPP-4i are known to effectively improve glucose control and reduce glucotoxicity by suppressing glucagon secretion and promoting GSIS through GLP-1- dependent and GLP-1-independent mechanisms. Also, the use of vitamin D and DPP-4i has proven to be safe in the context of diabetes (including autoimmune diabetes) and both these agents are relatively inexpensive.

In conclusion, large-scale, long-term, prospective randomized controlled trials are therefore required to confirm the aforementioned preliminary findings and determine the ability of VIDPP-4i to counteract beta-cell autoimmunity, improve glucose control, preserve beta-cell mass and function, prolong clinical remission phase, sustain insulin independence stage, and slow down or delay the progression of autoimmune diabetes. Randomized controlled trials are particularly warranted in the context of LADA, given the scarcity of studies investigating the efficacy of immune interventions in this population [29]. As a matter of fact, LADA represents an ideal model for exploring the combined effects of vitamin D and DPP-4i on autoimmunity and beta-cell function, because this disease is typically associated with a slower and less severe immune-mediated beta-cell destruction compared to T1D. Therefore, LADA offers a wider window to test immune interventions that may slow down beta-cell failure.

Additionally, it would be interesting to investigate the use of VIDPP$4 \mathrm{i}$ as an immune intervention aimed to prevent the onset of clinical diabetes in subjects with genetic susceptibility to T1D or during the presymptomatic stages of the disease. Likewise, the use of VIDPP-4i may also be investigated in the context of solid organ or cell transplantation, particularly in T1D subjects who received kidney, pancreas or islet transplantation, in order to assess whether this combination therapy is able to reduce immunosuppressant dose and immunosuppressionrelated toxicity, reduce glucotoxicity, improve glucose control and prolong allograft survival or prevent graft dysfunction. However, several aspects still remain to be addressed, such as: i) the identification of optimal doses and target circulating levels of vitamin D and DPP-4i required to achieve and maintain the anti-inflammatory and immunomodulatory effects of such molecules in vivo; and ii) the interindividual heterogeneity of response to vitamin D and DPP-4i, which can be related to a number of factors (e.g., genetic or environmental factors). Future mechanistic studies and clinical trials will certainly help to answer these questions.

\section{Funding}

This article did not receive any specific grant from funding agencies in the public, commercial, or not-for-profit sectors.

\section{Declaration of Competing Interest}

The authors declare that they have no competing financial interests or personal relationship that could have influenced the work reported in this paper.

\section{Acknowledgments}

Figure 1 was created with images adapted from Servier Medical Art licensed under a Creative Commons Attribution 3.0 Unported License (https://smart.servier.com/).

\section{References}

[1] P. Pozzilli, S. Pieralice, Latent Autoimmune Diabetes in Adults: Current Status and New Horizons, Endocrinol. Metab. (Seoul). 33 (2) (2018) 147-159.

[2] S. Luo, X. Ma, X. Li, Z. Xie, Z. Zhou, Fulminant type 1 diabetes: A comprehensive review of an autoimmune condition, Diabet. Metab. Res. Rev. 36 (6) (2020), e3317.

[3] V.H.M. Tsang, R.T. McGrath, R.J. Clifton-Bligh, R.A. Scolyer, V. Jakrot, A. D. Guminski, et al., Checkpoint Inhibitor-Associated Autoimmune Diabetes Is Distinct From Type 1 Diabetes, J. Clin. Endocrinol. Metab. 104 (11) (2019) 5499-5506.

[4] M.A. Atkinson, G.S. Eisenbarth, A.W. Michels, Type 1 diabetes, Lancet 383 (9911) (2014) 69-82. 
[5] J. Ilonen, J. Lempainen, R. Veijola, The heterogeneous pathogenesis of type 1 diabetes mellitus, Nat. Rev. Endocrinol. 15 (11) (2019) 635-650.

[6] M. Rewers, J. Ludvigsson, Environmental risk factors for type 1 diabetes, Lancet 387 (10035) (2016) 2340-2348.

[7] M.E. Craig, K.W. Kim, S.R. Isaacs, M.A. Penno, E.E. Hamilton-Williams, J. J. Couper, et al., Early-life factors contributing to type 1 diabetes, Diabetologia 62 (10) (2019) 1823-1834.

[8] K. Koivusaari, E. Syrjälä, S. Niinistö, H.M. Takkinen, S. Ahonen, M. Åkerlund, et al., Consumption of differently processed milk products in infancy and early childhood and the risk of islet autoimmunity, Br. J. Nutr. 1-8 (2020).

[9] F. Collado-Mesa, A. Barceló, K.L. Arheart, S.E. Messiah, An ecological analysis of childhood-onset type 1 diabetes incidence and prevalence in Latin America, Rev. Panam. Salud Publica 15 (6) (2004) 388-394.

[10] T.R. Merriman, Type 1 diabetes, the A1 milk hypothesis and vitamin D deficiency, Diabetes Res. Clin. Pract. 83 (2) (2009) 149-156.

[11] W. Gepts, Pathologic anatomy of the pancreas in juvenile diabetes mellitus, Diabetes 14 (10) (1965) 619-633.

[12] P. Leete, A. Willcox, L. Krogvold, K. Dahl-Jørgensen, A.K. Foulis, S.J. Richardson, et al., Differential Insulitic Profiles Determine the Extent of $\beta$-Cell Destruction and the Age at Onset of Type 1 Diabetes, Diabetes 65 (5) (2016) 1362-1369.

[13] B.O. Roep, The role of T-cells in the pathogenesis of Type 1 diabetes: from cause to cure, Diabetologia 46 (3) (2003) 305-321.

[14] L.S. Walker, M. von Herrath, CD4 T cell differentiation in type 1 diabetes, Clin. Exp. Immunol. 183 (1) (2016) 16-29.

[15] S. Lindley, C.M. Dayan, A. Bishop, B.O. Roep, M. Peakman, T.I. Tree, Defective suppressor function in CD4(+)CD25(+) T-cells from patients with type 1 diabetes, Diabetes 54 (1) (2005) 92-99.

[16] T.M. Brusko, C.H. Wasserfall, M.J. Clare-Salzler, D.A. Schatz, M.A. Atkinson, Functional defects and the influence of age on the frequency of CD $4+$ CD25+ T cells in type 1 diabetes, Diabetes 54 (5) (2005) 1407-1414.

[17] F. Haseda, A. Imagawa, Y. Murase-Mishiba, J. Terasaki, T. Hanafusa, CD4 CD45RA- FoxP3high activated regulatory T cells are functionally impaired and related to residual insulin-secreting capacity in patients with type 1 diabetes, Clin. Exp. Immunol. 173 (2) (2013) 207-216.

[18] Y. Okubo, H. Torrey, J. Butterworth, H. Zheng, D.L. Faustman, Treg activation defect in type 1 diabetes: correction with TNFR2 agonism, Clin Transl Immunology. 5 (1) (2016), e56.

[19] C. Greenbaum, D. VanBuecken, S. Lord, Disease-Modifying Therapies in Type 1 Diabetes: A Look into the Future of Diabetes Practice, Drugs. 79 (1) (2019) 43-61.

[20] M. Fonolleda, M. Murillo, F. Vázquez, J. Bel, M. Vives-Pi, Remission Phase in Paediatric Type 1 Diabetes: New Understanding and Emerging Biomarkers, Horm. Res. Paediatr. 88 (5) (2017) 307-315.

[21] J.H. Pinkey, P.J. Bingley, P.A. Sawtell, D.B. Dunger, E.A. Gale, Presentation and progress of childhood diabetes mellitus: a prospective population-based study. The Bart's-Oxford Study Group, Diabetologia 37 (1) (1994) 70-74.

[22] T. Zhong, R. Tang, Y. Xie, F. Liu, X. Li, Z. Zhou, Frequency, clinical characteristics, and determinants of partial remission in type 1 diabetes: Different patterns in children and adults, J. Diabetes 12 (10) (2020) 761-768.

[23] S. Passanisi, G. Salzano, A. Gasbarro, V. Urzì Brancati, M. Mondio, G.B. Pajno, et al., Influence of Age on Partial Clinical Remission among Children with Newly Diagnosed Type 1 Diabetes, Int. J. Environ. Res. Public Health 17 (13) (2020).

[24] M. Abdul-Rasoul, H. Habib, M. Al-Khouly, 'The honeymoon phase' in children with type 1 diabetes mellitus: frequency, duration, and influential factors, Pediatr. Diabet. 7 (2) (2006) 101-107.

[25] H. Aly, P. Gottlieb, The honeymoon phase: intersection of metabolism and immunology, Curr. Opin. Endocrinol. Diabetes Obes. 16 (4) (2009) 286-292.

[26] A. Jörns, D. Wedekind, J. Jähne, S. Lenzen, Pancreas Pathology of Latent Autoimmune Diabetes in Adults (LADA) in Patients and in a LADA Rat Model Compared With Type 1 Diabetes, Diabetes 69 (4) (2020) 624-633.

[27] S. Fourlanos, F. Dotta, C.J. Greenbaum, J.P. Palmer, O. Rolandsson, P.G. Colman, et al., Latent autoimmune diabetes in adults (LADA) should be less latent, Diabetologia 48 (11) (2005) 2206-2212.

[28] E. Maddaloni, C. Moretti, C. Mignogna, R. Buzzetti, Adult-onset autoimmune diabetes in 2020: An update, Maturitas 137 (2020) 37-44.

[29] R. Buzzetti, T. Tuomi, D. Mauricio, M. Pietropaolo, Z. Zhou, P. Pozzilli, et al. Management of Latent Autoimmune Diabetes in Adults: A Consensus Statement From an International Expert Panel, Diabetes 69 (10) (2020) 2037-2047.

[30] L.S. Farhy, A.L. McCall, Optimizing reduction in basal hyperglucagonaemia to repair defective glucagon counterregulation in insulin deficiency, Diabetes Obes. Metab. 13 (Suppl 1) (2011) 133-143.

[31] S.C. Gunawardana, M. Infante, Brown adipose tissue transplantation as a promising approach for insulin-independent reversal of type 1 diabetes: animal studies and clinical perspectives, Cell R4 8 (2020), e2986.

[32] M. Brissova, R. Haliyur, D. Saunders, S. Shrestha, C. Dai, D.M. Blodgett, et al., c Cell Function and Gene Expression Are Compromised in Type 1 Diabetes, Cell Rep. 22 (10) (2018) 2667-2676.

[33] T.O. Mundinger, Q. Mei, A.K. Foulis, C.L. Fligner, R.L. Hull, G.J. Taborsky, Human Type 1 Diabetes Is Characterized by an Early, Marked, Sustained, and Islet-Selective Loss of Sympathetic Nerves, Diabetes 65 (8) (2016) 2322-2330.

[34] P. Seiron, A. Wiberg, E. Kuric, L. Krogvold, F.L. Jahnsen, K. Dahl-Jørgensen, et al., Characterisation of the endocrine pancreas in type 1 diabetes: islet size is maintained but islet number is markedly reduced, J. Pathol. Clin. Res. 5 (4) (2019) 248-255.

[35] L. Alexandre-Heymann, R. Mallone, C. Boitard, R. Scharfmann, E. Larger, Structure and function of the exocrine pancreas in patients with type 1 diabetes, Rev. Endocr. Metab. Disord. 20 (2) (2019) 129-149.
[36] O. Skog, O. Korsgren, On the dynamics of the human endocrine pancreas and potential consequences for the development of type 1 diabetes, Acta Diabetol. 57 (4) (2020) 503-511.

[37] J.J. Wright, D.C. Saunders, C. Dai, G. Poffenberger, B. Cairns, D.V. Serreze, et al., Decreased pancreatic acinar cell number in type 1 diabetes, Diabetologia 63 (7) (2020) 1418-1423.

[38] G.S. Eisenbarth, Type I diabetes mellitus. A chronic autoimmune disease, N. Engl. J. Med. 314 (21) (1986) 1360-1368.

[39] H.A. Keenan, J.K. Sun, J. Levine, A. Doria, L.P. Aiello, G. Eisenbarth, et al., Residual insulin production and pancreatic B-cell turnover after 50 years of diabetes: Joslin Medalist Study, Diabetes 59 (11) (2010) 2846-2853.

[40] R.A. Oram, T.J. McDonald, B.M. Shields, M.M. Hudson, M.H. Shepherd, S. Hammersley, et al., Most people with long-duration type 1 diabetes in a large population-based study are insulin microsecretors, Diabet. Care 38 (2) (2015) 323-328.

[41] C.J. Lam, D.R. Jacobson, M.M. Rankin, A.R. Cox, J.A. Kushner, $\beta$ Cells Persist in T1D Pancreata Without Evidence of Ongoing $\beta$-Cell Turnover or Neogenesis, J. Clin. Endocrinol. Metab. 102 (8) (2017) 2647-2659.

[42] R.A. Oram, E.K. Sims, C. Evans-Molina, Beta cells in type 1 diabetes: mass and function; sleeping or dead? Diabetologia 62 (4) (2019) 567-577.

[43] M. Infante, C. Ricordi, Editorial - Moving forward on the pathway of targeted immunotherapies for type 1 diabetes: the importance of disease heterogeneity, Eur. Rev. Med. Pharmacol. Sci. 23 (19) (2019) 8702-8704.

[44] A. Petrone, A. Galgani, M. Spoletini, I. Alemanno, S. Di Cola, G. Bassotti, et al., Residual insulin secretion at diagnosis of type 1 diabetes is independently associated with both, age of onset and HLA genotype, Diabet. Metab. Res. Rev. 21 (3) (2005) 271-275.

[45] C.J. Greenbaum, C.A. Beam, D. Boulware, S.E. Gitelman, P.A. Gottlieb, K. C. Herold, et al., Fall in C-peptide during first 2 years from diagnosis: evidence of at least two distinct phases from composite Type 1 Diabetes TrialNet data, Diabetes 61 (8) (2012) 2066-2073.

[46] H.B. Mortensen, P.G. Swift, R.W. Holl, P. Hougaard, L. Hansen, H. Bjoerndalen, et al., Multinational study in children and adolescents with newly diagnosed type 1 diabetes: association of age, ketoacidosis, HLA status, and autoantibodies on residual beta-cell function and glycemic control 12 months after diagnosis, Pediatr. Diabet. 11 (4) (2010) 218-226.

[47] M.J. Dufort, C.J. Greenbaum, C. Speake, P.S. Linsley, Cell type-specific immune phenotypes predict loss of insulin secretion in new-onset type 1 diabetes, JCI Insight. 4 (4) (2019).

[48] P. Leete, R.A. Oram, T.J. McDonald, B.M. Shields, C. Ziller, A.T. Hattersley, et al., Studies of insulin and proinsulin in pancreas and serum support the existence of aetiopathological endotypes of type 1 diabetes associated with age at diagnosis, Diabetologia 63 (6) (2020) 1258-1267.

[49] S. Arif, P. Leete, V. Nguyen, K. Marks, N.M. Nor, M. Estorninho, et al., Blood and islet phenotypes indicate immunological heterogeneity in type 1 diabetes, Diabetes 63 (11) (2014) 3835-3845.

[50] X. Niu, S. Luo, X. Li, Z. Xie, Y. Xiang, G. Huang, et al., Identification of a distinct phenotype of elderly latent autoimmune diabetes in adults: LADA China Study 8, Diabet. Metab. Res. Rev. 35 (1) (2019), e3068.

[51] Effect of intensive therapy on residual beta-cell function in patients with type 1 diabetes in the diabetes control and complications trial. A randomized, controlled trial. The Diabetes Control and Complications Trial Research Group. Ann Intern Med. 1998;128(7):517-23.

[52] M.W. Steffes, S. Sibley, M. Jackson, W. Thomas, Beta-cell function and the development of diabetes-related complications in the diabetes control and complications trial, Diabet. Care 26 (3) (2003) 832-836.

[53] F.W. Gibb, J.A. McKnight, C. Clarke, M.W.J. Strachan, Preserved C-peptide secretion is associated with fewer low-glucose events and lower glucose variability on flash glucose monitoring in adults with type 1 diabetes, Diabetologia 63 (5) (2020) 906-914.

[54] Lachin JM, McGee P, Palmer JP, Group DER. Impact of C-peptide preservation on metabolic and clinical outcomes in the Diabetes Control and Complications Trial. Diabetes. 2014;63(2):739-48.

[55] J.P. Palmer, G.A. Fleming, C.J. Greenbaum, K.C. Herold, L.D. Jansa, H. Kolb, et al., C-peptide is the appropriate outcome measure for type 1 diabetes clinical trials to preserve beta-cell function: report of an ADA workshop, 21-22 October 2001, Diabetes 53 (1) (2004) 250-264.

[56] J.S. Skyler, Hope vs hype: where are we in type 1 diabetes? Diabetologia 61 (3) (2018) 509-516.

[57] J.S. Skyler, Prevention and reversal of type 1 diabetes-past challenges and future opportunities, Diabet. Care 38 (6) (2015) 997-1007.

[58] N.J. Woittiez, B.O. Roep, Impact of disease heterogeneity on treatment efficacy of immunotherapy in Type 1 diabetes: different shades of gray, Immunotherapy 7 (2) (2015) 163-174.

[59] M.M. Pinheiro, F.M. Pinheiro, M.A. Torres, Four-year clinical remission of type 1 diabetes mellitus in two patients treated with sitagliptin and vitamin D3, Endocrinol. Diabet. Metab. Case Rep. 2016 (2016).

[60] M.M. Lima-Martínez, E. Guerra-Alcalá, M. Contreras, J. Nastasi, J.A. Noble, C. Polychronakos, One year remission of type 1 diabetes mellitus in a patient treated with sitagliptin, Endocrinol. Diabet. Metab. Case Rep. 2014 (2014), 140072.

[61] M.A. Gabbay, M.N. Sato, C. Finazzo, A.J. Duarte, S.A. Dib, Effect of cholecalciferol as adjunctive therapy with insulin on protective immunologic profile and decline of residual $\beta$-cell function in new-onset type 1 diabetes mellitus, Arch. Pediatr. Adolesc. Med. 166 (7) (2012) 601-607. 
[62] D.A. Baidal, C. Ricordi, M. Garcia-Contreras, A. Sonnino, A. Fabbri, Combination high-dose omega-3 fatty acids and high-dose cholecalciferol in new onset type 1 diabetes: a potential role in preservation of beta-cell mass, Eur. Rev. Med. Pharmacol. Sci. 20 (15) (2016) 3313-3318.

[63] F. Cadario, S. Savastio, R. Ricotti, A.M. Rizzo, D. Carrera, L. Maiuri, et al., Administration of vitamin D and high dose of omega 3 to sustain remission of type 1 diabetes, Eur. Rev. Med. Pharmacol. Sci. 22 (2) (2018) 512-515.

[64] M.M. Pinheiro, F.M.M. Pinheiro, M.L. Trabachin, Dipeptidyl peptidase-4 inhibitors (DPP-4i) combined with vitamin D3: An exploration to treat new-onset type 1 diabetes mellitus and latent autoimmune diabetes in adults in the future, Int. Immunopharmacol. 57 (2018) 11-17.

[65] The Official Journal of ATTD Advanced Technologies \& Treatments for Diabetes Conference Madrid, Spain-February 19-22, 2020. Diabetes Technol Ther. 2020;22 (S1):A1-A250. 127/Abstract ID 592.

[66] Z. Zhang, X. Yan, C. Wu, X. Pei, X. Li, X. Wang, et al., Adding vitamin D3 to the dipeptidyl peptidase-4 inhibitor saxagliptin has the potential to protect $\beta$-cell function in LADA patients: A 1-year pilot study, Diabet. Metab. Res. Rev. 36 (5) (2020), e3298.

[67] E. Rapti, S. Karras, M. Grammatiki, A. Mousiolis, X. Tsekmekidou, E. Potolidis, e al., Combined treatment with sitagliptin and vitamin D in a patient with latent autoimmune diabetes in adults, Endocrinol. Diabet. Metab. Case Rep. 2016 (2016), 150136

[68] X. Li, L. Liao, X. Yan, G. Huang, J. Lin, M. Lei, et al., Protective effects of 1-alphahydroxyvitamin D3 on residual beta-cell function in patients with adult-onset latent autoimmune diabetes (LADA), Diabet. Metab. Res. Rev. 25 (5) (2009) $411-416$.

[69] O.E. Johansen, B.O. Boehm, V. Grill, P.A. Torjesen, S. Bhattacharya, S. Patel, et al., C-peptide levels in latent autoimmune diabetes in adults treated with linagliptin versus glimepiride: exploratory results from a 2-year double-blind, randomized, controlled study, Diabet. Care 37 (1) (2014) e11-e12.

[70] S. Christakos, P. Dhawan, A. Verstuyf, L. Verlinden, G. Carmeliet, Vitamin D: Metabolism, Molecular Mechanism of Action, and Pleiotropic Effects, Physiol. Rev. 96 (1) (2016) 365-408.

[71] S. Pilz, W. März, K.D. Cashman, M.E. Kiely, S.J. Whiting, M.F. Holick, et al., Rationale and Plan for Vitamin D Food Fortification: A Review and Guidance Paper, Front Endocrinol (Lausanne). 9 (2018) 373.

[72] K.D. Cashman, E.G. van den Heuvel, R.J. Schoemaker, D.P. Prévéraud, H. M. Macdonald, J. Arcot, 25-Hydroxyvitamin D as a Biomarker of Vitamin D Status and Its Modeling to Inform Strategies for Prevention of Vitamin D Deficiency within the Population, Adv. Nutr. 8 (6) (2017) 947-957.

[73] G. Bivona, B. Lo Sasso, G. Iacolino, C.M. Gambino, C. Scazzone, L. Agnello, et al., Standardized measurement of circulating vitamin D [25(OH)D] and its putative role as a serum biomarker in Alzheimer's disease and Parkinson's disease, Clin. Chim. Acta 497 (2019) 82-87.

[74] M. Caprio, M. Infante, M. Calanchini, C. Mammi, A. Fabbri, Vitamin D: not just the bone. Evidence for beneficial pleiotropic extraskeletal effects, Eat Weight Disord. 22 (1) (2017) 27-41.

[75] L. Mahmoudi, S. Asadi, Z. Al-Mousavi, R. Niknam, A randomized controlled clinical trial comparing calcitriol versus cholecalciferol supplementation to reduce insulin resistance in patients with non-alcoholic fatty liver disease, Clin. Nutr. (2020).

[76] M. Caprio, C. Mammi, G.M. Rosano, Vitamin D: a novel player in endothelial function and dysfunction, Arch. Med. Sci. 8 (1) (2012) 4-5.

[77] G. Bivona, L. Agnello, C. Bellia, G. Iacolino, C. Scazzone, B. Lo Sasso, et al., NonSkeletal Activities of Vitamin D: From Physiology to Brain Pathology, Medicina (Kaunas) 55 (7) (2019).

[78] D. Gatti, L. Idolazzi, A. Fassio, Vitamin D: not just bone, but also immunity, Minerva Med 107 (6) (2016) 452-460.

[79] D.D. Bikle, Vitamin D and bone, Curr. Osteoporos. Rep. 10 (2) (2012) 151-159.

[80] A. Valcour, F. Blocki, D.M. Hawkins, S.D. Rao, Effects of age and serum 25-OHvitamin D on serum parathyroid hormone levels, J. Clin. Endocrinol. Metab. 97 (11) (2012) 3989-3995.

[81] A. Fabbri, M. Infante, C. Ricordi, Editorial - Vitamin D status: a key modulator of innate immunity and natural defense from acute viral respiratory infections, Eur. Rev. Med. Pharmacol. Sci. 24 (7) (2020) 4048-4052.

[82] P.J. Martens, C. Gysemans, A. Verstuyf, A.C. Mathieu, Vitamin D's Effect on Immune Function, Nutrients 12 (5) (2020).

[83] A.I. Trochoutsou, V. Kloukina, K. Samitas, G. Xanthou, Vitamin-D in the Immune System: Genomic and Non-Genomic Actions, Mini Rev. Med. Chem. 15 (11) (2015) 953-963.

[84] B. Prietl, G. Treiber, T.R. Pieber, K. Amrein, Vitamin D and immune function, Nutrients. 5 (7) (2013) 2502-2521.

[85] J.H. White, Vitamin D metabolism and signaling in the immune system, Rev. Endocr. Metab. Disord. 13 (1) (2012) 21-29.

[86] T. Monkawa, T. Yoshida, M. Hayashi, T. Saruta, Identification of 25-hydroxyvitamin D3 1alpha-hydroxylase gene expression in macrophages, Kidney Int. 58 (2) (2000) 559-568.

[87] H. Sigmundsdottir, J. Pan, G.F. Debes, C. Alt, A. Habtezion, D. Soler, et al., DCs metabolize sunlight-induced vitamin D3 to 'program' T cell attraction to the epidermal chemokine CCL27, Nat. Immunol. 8 (3) (2007) 285-293.

[88] L. Overbergh, B. Decallonne, D. Valckx, A. Verstuyf, J. Depovere, J. Laureys, et al., Identification and immune regulation of 25-hydroxyvitamin D-1-alphahydroxylase in murine macrophages, Clin. Exp. Immunol. 120 (1) (2000) $139-146$.
[89] K. Stoffels, L. Overbergh, A. Giulietti, L. Verlinden, R. Bouillon, C. Mathieu, Immune regulation of 25-hydroxyvitamin-D3-1alpha-hydroxylase in human monocytes, J. Bone Miner. Res. 21 (1) (2006) 37-47.

[90] S. Chen, G.P. Sims, X.X. Chen, Y.Y. Gu, P.E. Lipsky, Modulatory effects of 1,25dihydroxyvitamin D3 on human B cell differentiation, J. Immunol. 179 (3) (2007) $1634-1647$.

[91] P.T. Liu, S. Stenger, D.H. Tang, R.L. Modlin, Cutting edge: vitamin D-mediated human antimicrobial activity against Mycobacterium tuberculosis is dependent on the induction of cathelicidin, J. Immunol. 179 (4) (2007) 2060-2063.

[92] T.T. Wang, F.P. Nestel, V. Bourdeau, Y. Nagai, Q. Wang, J. Liao, et al., Cutting edge: 1,25-dihydroxyvitamin D3 is a direct inducer of antimicrobial peptide gene expression, J. Immunol. 173 (5) (2004) 2909-2912.

[93] P.T. Liu, M. Schenk, V.P. Walker, P.W. Dempsey, M. Kanchanapoomi, M. Wheelwright, et al., Convergence of IL-1beta and VDR activation pathways in human TLR2/1-induced antimicrobial responses, PLoS ONE 4 (6) (2009), e5810.

[94] G. Bivona, L. Agnello, B. Lo Sasso, C. Scazzone, D. Butera, C.M. Gambino, et al., Vitamin D in malaria: more hypotheses than clues, Heliyon. 5 (2) (2019), e01183.

[95] D. Zisi, A. Challa, A. Makis, The association between vitamin D status and infectious diseases of the respiratory system in infancy and childhood, Hormones (Athens). 18 (4) (2019) 353-363.

[96] M. Infante, A. Buoso, M. Pieri, S. Lupisella, M. Nuccetelli, S. Bernardini, et al., Low Vitamin D Status at Admission as a Risk Factor for Poor Survival in Hospitalized Patients With COVID-19: An Italian Retrospective Study, J. Am. Coll. Nutr. (2021), https://doi.org/10.1080/07315724.2021.1877580 [Epub ahead of print].

[97] H. Korf, M. Wenes, B. Stijlemans, T. Takiishi, S. Robert, M. Miani, et al., 1,25Dihydroxyvitamin D3 curtails the inflammatory and T cell stimulatory capacity of macrophages through an IL-10-dependent mechanism, Immunobiology 217 (12) (2012) 1292-1300.

[98] X. Zhang, M. Zhou, Y. Guo, Z. Song, B. Liu, 1,25-Dihydroxyvitamin D 3 Promotes High Glucose-Induced M1 Macrophage Switching to M2 via the VDR-PPAR $\gamma$ Signaling Pathway, Biomed. Res. Int. 2015 (2015), 157834.

[99] Y. Zhang, D.Y. Leung, B.N. Richers, Y. Liu, L.K. Remigio, D.W. Riches, et al., Vitamin D inhibits monocyte/macrophage proinflammatory cytokine production by targeting MAPK phosphatase-1, J. Immunol. 188 (5) (2012) 2127-2135.

[100] G.B. Ferreira, E. van Etten, A. Verstuyf, M. Waer, L. Overbergh, C. Gysemans, et al., 1,25-Dihydroxyvitamin D3 alters murine dendritic cell behaviour in vitro and in vivo, Diabet. Metab. Res. Rev. 27 (8) (2011) 933-941.

[101] T.L. Van Belle, A.S. Vanherwegen, D. Feyaerts, P. De Clercq, A. Verstuyf, H. Korf, et al., 1,25-Dihydroxyvitamin D3 and its analog TX527 promote a stable regulatory $\mathrm{T}$ cell phenotype in T cells from type 1 diabetes patients, PLoS ONE 9 (10) (2014), e109194.

[102] L. Overbergh, B. Decallonne, M. Waer, O. Rutgeerts, D. Valckx, K.M. Casteels, et al., 1alpha, 25-dihydroxyvitamin D3 induces an autoantigen-specific T-helper $1 /$ T-helper 2 immune shift in NOD mice immunized with GAD65 (p524-543), Diabetes 49 (8) (2000) 1301-1307.

[103] J. Smolders, M. Thewissen, E. Peelen, P. Menheere, J.W. Tervaert, J. Damoiseaux, et al., Vitamin D status is positively correlated with regulatory T cell function in patients with multiple sclerosis, PLoS ONE 4 (8) (2009), e6635.

[104] A.P. Lysandropoulos, E. Jaquiéry, S. Jilek, G. Pantaleo, M. Schluep, R.A. Du Pasquier, Vitamin D has a direct immunomodulatory effect on CD8+ T cells of patients with early multiple sclerosis and healthy control subjects, J. Neuroimmunol. 233 (1-2) (2011) 240-244.

[105] M.R. von Essen, M. Kongsbak, P. Schjerling, K. Olgaard, N. Odum, C. Geisler, Vitamin D controls $\mathrm{T}$ cell antigen receptor signaling and activation of human T cells, Nat. Immunol. 11 (4) (2010) 344-349.

[106] Q. Zhou, S. Qin, J. Zhang, L. Zhon, Z. Pen, T. Xing, 1,25(OH)2D3 induces regulatory $\mathrm{T}$ cell differentiation by influencing the VDR/PLC- $\gamma 1$ /TGF- $\beta 1 /$ pathway, Mol. Immunol. 91 (2017 Nov) 156-164, https://doi.org/10.1016/j molimm.2017.09.006. Epub 2017 Sep 17.

[107] C. Scazzone, L. Agnello, G. Bivona, B. Lo Sasso, M. Ciaccio, Vitamin D and Genetic Susceptibility to Multiple Sclerosis, Biochem. Genet. 59 (1) (2021) 1-30.

[108] C. Scazzone, L. Agnello, P. Ragonese, B. Lo Sasso, C. Bellia, G. Bivona, et al., Association of CYP2R1 rs10766197 with MS risk and disease progression, J. Neurosci. Res. 96 (2) (2018) 297-304.

[109] G. Bivona, C.M. Gambino, G. Iacolino, M. Ciaccio, Vitamin D and the nervous system, Neurol. Res. 41 (9) (2019) 827-835.

[110] G. Bivona, L. Agnello, A. Pivetti, S. Milano, C. Scazzone, B.L. Sasso, et al., Association between hypovitaminosis D and systemic sclerosis: True or fake? Clin. Chim. Acta 458 (2016) 115-119.

[111] W. Dankers, E.M. Colin, J.P. van Hamburg, E. Lubberts, Vitamin D in Autoimmunity: Molecular Mechanisms and Therapeutic Potential, Front. Immunol. 7 (2016) 697.

[112] M. Infante, C. Ricordi, J. Sanchez, M.J. Clare-Salzler, N. Padilla, V. Fuenmayor, et al., Influence of Vitamin D on Islet Autoimmunity and Beta-Cell Function in Type 1 Diabetes, Nutrients. 11 (9) (2019).

[113] M.E. Miettinen, S. Niinistö, J. Honkanen, I. Erlund, M. Knip, S.M. Virtanen, The role of vitamin D in the aetiology of type 1 diabetes. Reply to Korsgren O [letter], Diabetologia 63 (6) (2020) 1281-1282.

[114] C. Ricordi, M. Clare-Salzler, M. Infante, C. Baggerly, J. Aliano, S. McDonnell, et al., Vitamin D and Omega 3 Field Study on Progression of Type 1 Diabetes, Cell R4 Repair Replace Regen Reprogram. 7 (2019).

[115] Y. Hou, A. Song, Y. Jin, Q. Xia, G. Song, X. Xing, A dose-response meta-analysis between serum concentration of 25-hydroxy vitamin D and risk of type 1 diabetes mellitus, Eur. J. Clin. Nutr. (2020). 
[116] J. Weng, Z. Zhou, L. Guo, D. Zhu, L. Ji, X. Luo, et al., Incidence of type 1 diabetes in China, 2010-13: population based study, BMJ 360 (2018), j5295.

[117] J.A. Staples, A.L. Ponsonby, L.L. Lim, A.J. McMichael, Ecologic analysis of some immune-related disorders, including type 1 diabetes, in Australia: latitude, regional ultraviolet radiation, and disease prevalence, Environ. Health Perspect. 111 (4) (2003) 518-523.

[118] Y.L. Chen, Y.C. Huang, Y.C. Qiao, W. Ling, Y.H. Pan, L.J. Geng, et al., Climates on incidence of childhood type 1 diabetes mellitus in 72 countries, Sci. Rep. 7 (1) (2017) 12810.

[119] P. Fsadni, C. Fsadni, S. Fava, S. Montefort, Correlation of worldwide incidence of type 1 diabetes (DiaMond) with prevalence of asthma and atopic eczema (ISAAC), Clin Respir J. 6 (1) (2012) 18-25.

[120] S.B. Mohr, C.F. Garland, E.D. Gorham, F.C. Garland, The association between ultraviolet B irradiance, vitamin D status and incidence rates of type 1 diabetes in 51 regions worldwide, Diabetologia 51 (8) (2008) 1391-1398.

[121] P. Pozzilli, S. Manfrini, A. Crinò, A. Picardi, C. Leomanni, V. Cherubini, et al., Low levels of 25-hydroxyvitamin D3 and 1,25-dihydroxyvitamin D3 in patients with newly diagnosed type 1 diabetes, Horm. Metab. Res. 37 (11) (2005) 680-683.

[122] F. Cadario, F. Prodam, S. Savastio, A. Monzani, A. Balafrej, G. Bellomo, et al., Vitamin D status and type 1 diabetes in children: evaluation according to latitude and skin color, Minerva Pediatr. 67 (3) (2015) 263-267.

[123] B. Littorin, P. Blom, A. Schölin, H.J. Arnqvist, G. Blohmé, J. Bolinder, et al., Lower levels of plasma 25-hydroxyvitamin D among young adults at diagnosis of autoimmune type 1 diabetes compared with control subjects: results from the nationwide Diabetes Incidence Study in Sweden (DISS), Diabetologia 49 (12) (2006) 2847-2852.

[124] V.V. Borkar, V.S. Devidayal, A.K. Bhalla, Low levels of vitamin D in North Indian children with newly diagnosed type 1 diabetes, Pediatr Diabetes. 11 (5) (2010) 345-350.

[125] M.A. Rasoul, M. Al-Mahdi, H. Al-Kandari, G.S. Dhaunsi, M.Z. Haider, Low serum vitamin-D status is associated with high prevalence and early onset of type-1 diabetes mellitus in Kuwaiti children, BMC Pediatr. 16 (2016) 95.

[126] G. Federico, A. Genoni, A. Puggioni, A. Saba, D. Gallo, E. Randazzo, et al., Vitamin D status, enterovirus infection, and type 1 diabetes in Italian children/ adolescents, Pediatr. Diabet. 19 (5) (2018) 923-929.

[127] N.M. Al-Daghri, O.S. Al-Attas, M.S. Alokail, K.M. Alkharfy, S.M. Yakout, N. J. Aljohani, et al., Lower vitamin D status is more common among Saudi adults with diabetes mellitus type 1 than in non-diabetics, BMC Public Health. 14 (2014) 153.

[128] H. Al-Zubeidi, L. Leon-Chi, R.S. Newfield, Low vitamin D level in pediatric patients with new onset type 1 diabetes is common, especially if in ketoacidosis, Pediatr. Diabet. 17 (8) (2016) 592-598.

[129] R.A. Daga, B.A. Laway, Z.A. Shah, S.A. Mir, S.K. Kotwal, A.H. Zargar, High prevalence of vitamin D deficiency among newly diagnosed youth-onset diabetes mellitus in north India, Arq Bras. Endocrinol. Metabol. 56 (7) (2012) 423-428.

[130] R.M. Greer, S.L. Portelli, B.S. Hung, G.J. Cleghorn, S.K. McMahon, J.A. Batch, et al., Serum vitamin D levels are lower in Australian children and adolescents with type 1 diabetes than in children without diabetes, Pediatr. Diabet. 14 (1) (2013) $31-41$.

[131] A. Gerasimidi Vazeou, O. Kordonouri, M. Witsch, J.M. Hermann, G. Forsander, C. de Beaufort, et al., Seasonality at the clinical onset of type 1 diabetes-Lessons from the SWEET database, Pediatr. Diabet. 17 (Suppl 23) (2016) 32-37.

[132] E.V. Moltchanova, N. Schreier, N. Lammi, M. Karvonen, Seasonal variation of diagnosis of Type 1 diabetes mellitus in children worldwide, Diabet. Med. 26 (7) (2009) 673-678.

[133] M.E. Miettinen, S. Niinistö, I. Erlund, D. Cuthbertson, A.M. Nucci, J. Honkanen, et al., Serum 25-hydroxyvitamin D concentration in childhood and risk of islet autoimmunity and type 1 diabetes: the TRIGR nested case-control ancillary study, Diabetologia 63 (4) (2020) 780-787.

[134] E. Hyppönen, E. Läärä, A. Reunanen, M.R. Järvelin, S.M. Virtanen, Intake of vitamin D and risk of type 1 diabetes: a birth-cohort study, Lancet 358 (9292) (2001) 1500-1503.

[135] U. Zeitz, K. Weber, D.W. Soegiarto, E. Wolf, R. Balling, R.G. Erben, Impaired insulin secretory capacity in mice lacking a functional vitamin D receptor, FASEB J. 17 (3) (2003) 509-511.

[136] R. Bland, D. Markovic, C.E. Hills, S.V. Hughes, S.L. Chan, P.E. Squires, et al., Expression of 25-hydroxyvitamin D3-1alpha-hydroxylase in pancreatic islets, J. Steroid Biochem. Mol. Biol. 89-90 (1-5) (2004) 121-125.

[137] D. Zehnder, R. Bland, M.C. Williams, R.W. McNinch, A.J. Howie, P.M. Stewart, et al., Extrarenal expression of 25-hydroxyvitamin d(3)-1 alpha-hydroxylase, J. Clin. Endocrinol. Metab. 86 (2) (2001) 888-894.

[138] E.E. Delvin, Importance of vitamin D in insulin resistance, Bull Acad Natl Med. 195 (4-5) (2011) 1091-1102, discussion 102-3.

[139] J.A. Johnson, J.P. Grande, P.C. Roche, R. Kumar, Immunohistochemical localization of the 1,25(OH)2D3 receptor and calbindin D28k in human and rat pancreas, Am. J. Physiol. 267 (3 Pt 1) (1994) E356-E360.

[140] B. Maestro, N. Dávila, M.C. Carranza, C. Calle, Identification of a Vitamin D response element in the human insulin receptor gene promoter, J. Steroid Biochem. Mol, Biol. 84 (2-3) (2003) 223-230.

[141] Z. Wei, E. Yoshihara, N. He, N. Hah, W. Fan, A.F.M. Pinto, et al., Vitamin D Switches BAF Complexes to Protect $\beta$ Cells, Cell 173 (5) (2018) 1135-1149.e15.

[142] M. Morró, L. Vilà, S. Franckhauser, C. Mallol, G. Elias, T. Ferré, et al., Vitamin D Receptor Overexpression in $\beta$-Cells Ameliorates Diabetes in Mice, Diabetes 69 (5) (2020) 927-939.
[143] K. Viloria, D. Nasteska, L.J.B. Briant, S. Heising, D.P. Larner, N.H.F. Fine, et al., Vitamin-D-Binding Protein Contributes to the Maintenance of $\alpha$ Cell Function and Glucagon Secretion, Cell Rep. 31 (11) (2020), 107761.

[144] G. Treiber, B. Prietl, E. Fröhlich-Reiterer, E. Lechner, A. Ribitsch, M. Fritsch, et al., Cholecalciferol supplementation improves suppressive capacity of regulatory Tcells in young patients with new-onset type 1 diabetes mellitus - A randomized clinical trial, Clin. Immunol. 161 (2) (2015) 217-224.

[145] D.T. Papadimitriou, C. Marakaki, A. Fretzayas, P. Nicolaidou, A. Papadimitriou, Negativation of type 1 diabetes-associated autoantibodies to glutamic acid decarboxylase and insulin in children treated with oral calcitriol, J. Diabet. 5 (3) (2013) 344-348.

[146] H. Mazahery, P.R. von Hurst, Factors Affecting 25-Hydroxyvitamin D Concentration in Response to Vitamin D Supplementation, Nutrients 7 (7) (2015) $5111-5142$.

[147] M. Infante, C. Ricordi, D.A. Baidal, R. Alejandro, G. Lanzoni, B. Sears, et al., VITAL study: an incomplete picture? Eur. Rev. Med. Pharmacol. Sci. 23 (7) (2019) 3142-3147.

[148] A. Fassio, G. Adami, M. Rossini, A. Giollo, C. Caimmi, R. Bixio, et al., Pharmacokinetics of Oral Cholecalciferol in Healthy Subjects with Vitamin D Deficiency: A Randomized Open-Label Study, Nutrients. 12 (6) (2020).

[149] P.J. McCullough, D.S. Lehrer, J. Amend, Daily oral dosing of vitamin D3 using 5000 TO 50,000 international units a day in long-term hospitalized patients: Insights from a seven year experience, J. Steroid Biochem. Mol. Biol. 189 (2019) 228-239.

[150] G. Federico, D. Focosi, B. Marchi, E. Randazzo, M. De Donno, F. Vierucci, et al., Administering 25-hydroxyvitamin D3 in vitamin D-deficient young type 1A diabetic patients reduces reactivity against islet autoantigens, Clin. Nutr. 33 (6) (2014) 1153-1156.

[151] T. Du, Z.G. Zhou, S. You, G. Huang, J. Lin, L. Yang, et al., Modulation of monocyte hyperresponsiveness to TLR ligands by 1,25-dihydroxy-vitamin D3 from LADA and T2DM, Diabetes Res. Clin. Pract. 83 (2) (2009) 208-214.

[152] J.E. Löfvenborg, T. Andersson, P.O. Carlsson, M. Dorkhan, L. Groop, M. Martinell, et al., Fatty fish consumption and risk of latent autoimmune diabetes in adults, Nutr. Diabetes 4 (2014), e139.

[153] C. Klemann, L. Wagner, M. Stephan, S. von Hörsten, Cut to the chase: a review of CD26/dipeptidyl peptidase-4's (DPP4) entanglement in the immune system, Clin. Exp. Immunol. 185 (1) (2016) 1-21.

[154] P. Augstein, G. Naselli, T. Loudovaris, W.J. Hawthorne, P. Campbell, E. BandalaSanchez, et al., Localization of dipeptidyl peptidase-4 (CD26) to human pancreatic ducts and islet alpha cells, Diabetes Res. Clin. Pract. 110 (3) (2015) 291-300.

[155] M.M. Pinheiro, M.J. Pinheiro, M.M.F. Pinheiro, Editorial - COVID-19 pandemic: is it time to learn about DPP-4/CD26? Cell R4 8 (2020), e2835.

[156] M.D. Gorrell, V. Gysbers, G.W. McCaughan, CD26: a multifunctional integral membrane and secreted protein of activated lymphocytes, Scand. J. Immunol. 54 (3) (2001) 249-264.

[157] R. Pacheco, J.M. Martinez-Navio, M. Lejeune, N. Climent, H. Oliva, J.M. Gatell, et al., CD26, adenosine deaminase, and adenosine receptors mediate costimulatory signals in the immunological synapse, Proc Natl Acad Sci U S A. 102 (27) (2005) 9583-9588.

[158] K. Ohnuma, M. Uchiyama, T. Yamochi, K. Nishibashi, O. Hosono, N. Takahashi, et al., Caveolin-1 triggers T-cell activation via CD26 in association with CARMA1, J. Biol. Chem. 282 (13) (2007) 10117-10131.

[159] R. Hatano, K. Ohnuma, J. Yamamoto, N.H. Dang, C. Morimoto, CD26-mediated co-stimulation in human CD8(+) T cells provokes effector function via proinflammatory cytokine production, Immunology 138 (2) (2013) 165-172.

[160] R. Hatano, K. Ohnuma, H. Otsuka, E. Komiya, I. Taki, S. Iwata, et al., CD26mediated induction of EGR2 and IL-10 as potential regulatory mechanism for CD26 costimulatory pathway, J. Immunol. 194 (3) (2015) 960-972.

[161] C.A. Garcia Santana, J.W. Tung, S. Gulnik, Human treg cells are characterized by low/negative CD6 expression, Cytometry A. 85 (10) (2014) 901-908.

[162] F.J. Salgado, A. Pérez-Díaz, N.M. Villanueva, O. Lamas, P. Arias, M. Nogueira, CD26: a negative selection marker for human Treg cells, Cytometry A. 81 (10) (2012) 843-855.

[163] B. Bengsch, B. Seigel, T. Flecken, J. Wolanski, H.E. Blum, R. Thimme, Human Th17 cells express high levels of enzymatically active dipeptidylpeptidase IV (CD26), J. Immunol. 188 (11) (2012) 5438-5447.

[164] X. Zhao, W. Wang, K. Zhang, J. Yang, H. Fuchs, H. Fan, Involvement of CD26 in Differentiation and Functions of Th1 and Th17 Subpopulations of T Lymphocytes, J Immunol Res. 2021 (2021) 6671410.

[165] K. Ohnuma, T. Yamochi, M. Uchiyama, K. Nishibashi, N. Yoshikawa, N. Shimizu, et al., CD26 up-regulates expression of CD86 on antigen-presenting cells by means of caveolin-1, Proc. Natl. Acad. Sci. U S A. 101 (39) (2004) 14186-14191.

[166] R.P. Dong, J. Kameoka, M. Hegen, T. Tanaka, Y. Xu, S.F. Schlossman, et al., Characterization of adenosine deaminase binding to human CD26 on T cells and its biologic role in immune response, J. Immunol. 156 (4) (1996) 1349-1355.

[167] C. Morimoto, S.F. Schlossman, The structure and function of CD26 in the T-cell immune response, Immunol. Rev. 161 (1998) 55-70.

[168] M.M. Pinheiro, C.L. Stoppa, C.J. Valduga, C.E. Okuyama, R. Gorjão, R.M. Pereira, et al., Sitagliptin inhibit human lymphocytes proliferation and Th1/Th17 differentiation in vitro, Eur. J. Pharm. Sci. 100 (2017) 17-24.

[169] D.J. Drucker, Mechanisms of Action and Therapeutic Application of Glucagon-like Peptide-1, Cell Metab. 27 (4) (2018) 740-756.

[170] Y. Seino, M. Fukushima, D. Yabe, GIP and GLP-1, the two incretin hormones: Similarities and differences, J. Diabet. Investig. 1 (1-2) (2010) 8-23. 
[171] A. Vella, Mechanism of action of DPP-4 inhibitors-new insights, J. Clin. Endocrinol. Metab. 97 (8) (2012) 2626-2628.

[172] D. Dicker, DPP-4 inhibitors: impact on glycemic control and cardiovascular risk factors, Diabetes Care 34 (Suppl 2) (2011) S276-S278.

[173] C. Guida, L.J. McCulloch, M. Godazgar, S.D. Stephen, C. Baker, D. Basco, et al., Sitagliptin and Roux-en-Y gastric bypass modulate insulin secretion via regulation of intra-islet PYY, Diabetes Obes. Metab. 20 (3) (2018) 571-581.

[174] A.R. Aroor, J.R. Sowers, G. Jia, V.G. DeMarco, Pleiotropic effects of the dipeptidylpeptidase-4 inhibitors on the cardiovascular system, Am. J. Physiol Heart Circ. Physiol. 307 (4) (2014) H477-H492.

[175] A. Avogaro, G.P. Fadini, The effects of dipeptidyl peptidase-4 inhibition on microvascular diabetes complications, Diabet. Care 37 (10) (2014) 2884-2894.

[176] A. Makdissi, H. Ghanim, M. Vora, K. Green, S. Abuaysheh, A. Chaudhuri, et al., Sitagliptin exerts an antinflammatory action, J. Clin. Endocrinol. Metab. 97 (9) (2012) 3333-3341.

[177] N. Satoh-Asahara, Y. Sasaki, H. Wada, M. Tochiya, A. Iguchi, R. Nakagawachi, et al., A dipeptidyl peptidase-4 inhibitor, sitagliptin, exerts anti-inflammatory effects in type 2 diabetic patients, Metabolism. 62 (3) (2013) 347-351.

[178] P. Shah, A. Ardestani, G. Dharmadhikari, S. Laue, D.M. Schumann, J. Kerr-Conte, et al., The DPP-4 inhibitor linagliptin restores $\beta$-cell function and survival in human isolated islets through GLP-1 stabilization, J. Clin. Endocrinol. Metab. 98 (7) (2013) E1163-E1172

[179] J. Újhelyi, Z. Újhelyi, A. Szalai, J.F. László, M. Cayasso, M. Vecsernyés, et al., Analgesic and anti-inflammatory effectiveness of sitagliptin and vildagliptin in mice, Regul. Pept. 194-195 (2014) 23-29.

[180] U.A. Kagal, N.B. Angadi, S.M. Matule, Effect of dipeptidyl peptidase 4 inhibitors on acute and subacute models of inflammation in male Wistar rats: An experimental study, Int. J. Appl. Basic Med. Res. 7 (1) (2017) 26-31.

[181] A.J. Tremblay, B. Lamarche, C.F. Deacon, S.J. Weisnagel, P. Couture, Effects of sitagliptin therapy on markers of low-grade inflammation and cell adhesion molecules in patients with type 2 diabetes, Metabolism 63 (9) (2014) 1141-1148.

[182] Y.C. Chen, T.H. Chen, C.C. Sun, J.Y. Chen, S.S. Chang, L. Yeung, et al., Dipeptidy peptidase- 4 inhibitors and the risks of autoimmune diseases in type 2 diabetes mellitus patients in Taiwan: a nationwide population-based cohort study, Acta Diabetol. 57 (10) (2020) 1181-1192.

[183] J. Mu, J. Woods, Y.P. Zhou, R.S. Roy, Z. Li, E. Zycband, et al., Chronic inhibition of dipeptidyl peptidase-4 with a sitagliptin analog preserves pancreatic beta-cel mass and function in a rodent model of type 2 diabetes, Diabetes 55 (6) (2006) 1695-1704.

[184] B.A. Omar, J. Vikman, M.S. Winzell, U. Voss, E. Ekblad, J.E. Foley, et al., Enhanced beta cell function and anti-inflammatory effect after chronic treatment with the dipeptidyl peptidase-4 inhibitor vildagliptin in an advanced-aged dietinduced obesity mouse model, Diabetologia 56 (8) (2013) 1752-1760.

[185] J.A. Pospisilik, J. Martin, T. Doty, J.A. Ehses, N. Pamir, F.C. Lynn, et al., Dipeptidyl peptidase IV inhibitor treatment stimulates beta-cell survival and islet neogenesis in streptozotocin-induced diabetic rats, Diabetes 52 (3) (2003) $741-750$.

[186] G. Argun-Kurum, F. Kaya-Dagistanli, M. Ozturk, DPP4 inhibitor induces beta cell regeneration and DDR-1 protein expression as an endocrine progenitor cell marker in neonatal STZ-diabetic rats, Pharmacol. Rep. 71 (4) (2019) 721-731.

[187] L.Y. Ansarullah, M. Holstein, B. DeRuyter, A. Rabinovitch, Z. Guo, Stimulating $\beta$-cell regeneration by combining a GPR119 agonist with a DPP-IV inhibitor, PLoS ONE 8 (1) (2013) e53345.

[188] J. Buteau, GLP-1 receptor signaling: effects on pancreatic beta-cell proliferation and survival, Diabet. Metab. 34 (Suppl 2) (2008) S73-S77.

[189] X. Wang, P. Zheng, G. Huang, L. Yang, Z. Zhou, Dipeptidyl peptidase-4(DPP-4) inhibitors: promising new agents for autoimmune diabetes, Clin. Exp. Med. 18 (4) (2018) 473-480.

[190] J. Jelsing, N. Vrang, S.B. van Witteloostuijn, M. Mark, T. Klein, The DPP4 inhibitor linagliptin delays the onset of diabetes and preserves $\beta$-cell mass in nonobese diabetic mice, J. Endocrinol. 214 (3) (2012) 381-387.

[191] S.J. Kim, C. Nian, D.J. Doudet, C.H. McIntosh, Dipeptidyl peptidase IV inhibition with MK0431 improves islet graft survival in diabetic NOD mice partially via Tcell modulation, Diabetes 58 (3) (2009) 641-651.

[192] S.J. Kim, C. Nian, C.H. McIntosh, Sitagliptin (MK0431) inhibition of dipeptidyl peptidase IV decreases nonobese diabetic mouse CD4+ T-cell migration through incretin-dependent and -independent pathways, Diabetes 59 (7) (2010) 1739-1750.

[193] N. Alonso, M.T. Julián, J. Carrascal, R. Colobran, I. Pujol-Autonell, S. RodriguezFernández, et al., Type 1 Diabetes Prevention in NOD Mice by Targeting DPPIV/ CD26 Is Associated with Changes in CD8 ${ }^{+} \mathrm{T}$ Effector Memory Subset, PLoS ONE 10 (11) (2015), e0142186.

[194] L. Tian, J. Gao, J. Hao, Y. Zhang, H. Yi, T.D. O'Brien, et al., Reversal of new-onset diabetes through modulating inflammation and stimulating beta-cell replication in nonobese diabetic mice by a dipeptidyl peptidase IV inhibitor, Endocrinology 151 (7) (2010) 3049-3060.

[195] M.R. Davanso, C. Caliari-Oliveira, C.E.B. Couri, D.T. Covas, A.M. de Oliveira Leal, J.C. Voltarelli, et al., DPP-4 Inhibition Leads to Decreased Pancreatic Inflammatory Profile and Increased Frequency of Regulatory T Cells in Experimental Type 1 Diabetes, Inflammation. 42 (2) (2019) 449-462.

[196] Q. Wang, M. Long, H. Qu, R. Shen, R. Zhang, J. Xu, et al., DPP-4 Inhibitors as Treatments for Type 1 Diabetes Mellitus: A Systematic Review and Meta-Analysis, J. Diabet. Res. 2018 (2018) 5308582.

[197] S.L. Ellis, E.G. Moser, J.K. Snell-Bergeon, A.S. Rodionova, R.M. Hazenfield, S. K. Garg, Effect of sitagliptin on glucose control in adult patients with Type 1 diabetes: a pilot, double-blind, randomized, crossover trial, Diabet. Med. 28 (10) (2011) 1176-1181.

[198] K.V. Hari Kumar, A. Shaikh, P. Prusty, Addition of exenatide or sitagliptin to insulin in new onset type 1 diabetes: a randomized, open label study, Diabet. Res. Clin. Pract. 100 (2) (2013) e55-e58.

[199] S.K. Garg, E.G. Moser, B.W. Bode, L.J. Klaff, W.R. Hiatt, C. Beatson, et al., Effect of sitagliptin on post-prandial glucagon and GLP-1 levels in patients with type 1 diabetes: investigator-initiated, double-blind, randomized, placebo-controlled trial, Endocr. Pract. 19 (1) (2013) 19-28.

[200] K.J. Griffin, P.A. Thompson, M. Gottschalk, J.H. Kyllo, A. Rabinovitch, Combination therapy with sitagliptin and lansoprazole in patients with recentonset type 1 diabetes (REPAIR-T1D): 12-month results of a multicentre, randomised, placebo-controlled, phase 2 trial, Lancet Diabet. Endocrinol. 2 (9) (2014) 710-718.

[201] W.L. Suarez-Pinzon, G.S. Cembrowski, A. Rabinovitch, Combination therapy with a dipeptidyl peptidase-4 inhibitor and a proton pump inhibitor restores normoglycaemia in non-obese diabetic mice, Diabetologia 52 (8) (2009) $1680-1682$.

[202] T. Varga, A. Somogyi, G. Barna, B. Wichmann, G. Nagy, K. Rácz, et al., Higher serum DPP-4 enzyme activity and decreased lymphocyte CD26 expression in type 1 diabetes, Pathol. Oncol. Res. 17 (4) (2011) 925-930.

[203] A. Iwabuchi, T. Kamoda, M. Saito, H. Nozue, I. Izumi, T. Hirano, et al., Serum dipeptidyl peptidase 4 activity in children with type 1 diabetes mellitus, J. Pediatr. Endocrinol. Metab. 26 (11-12) (2013) 1093-1097.

[204] S. Osawa, D. Kawamori, N. Katakami, M. Takahara, F. Sakamoto, T. Katsura, et al., Significant elevation of serum dipeptidyl peptidase-4 activity in young-adult type 1 diabetes, Diabetes Res. Clin. Pract. 113 (2016) 135-142.

[205] T. Varga, G. Firneisz, G. Nagy, A. Somogyi, Elevated serum dipeptidyl peptidase-4 activity in type 1 diabetes mellitus: a direct comparison, Orv. Hetil. 151 (22) (2010) 899-902.

[206] L. Duvnjak, K. Blaslov, M. Vučić Lovrenčić, Ć.J. Knežević, Persons with latent autoimmune diabetes in adults express higher dipeptidyl peptidase-4 activity compared to persons with type 2 and type 1 diabetes, Diabetes Res. Clin. Pract. 121 (2016) 119-126.

[207] L. Duvnjak, K. Blaslov, M.N. Perković, J.K. Cuća, Dipeptidyl peptidase-4 activity might be a link between tumour necrosis factor alpha and insulin resistance in type 1 diabetes, Endocrine 53 (2) (2016) 453-458.

[208] K. Kamoi, Y. Shinozaki, K. Furukawa, H. Sasaki, Decreased active GLP-1 response following large test meal in patients with type 1 diabetes using bolus insulin analogues, Endocr. J. 58 (10) (2011) 905-911.

[209] A.D. Dobrian, Q. Ma, J.W. Lindsay, K.A. Leone, K. Ma, J. Coben, et al., Dipeptidyl peptidase IV inhibitor sitagliptin reduces local inflammation in adipose tissue and in pancreatic islets of obese mice, Am. J. Physiol. Endocrinol. Metab. 300 (2) (2011) E410-E421.

[210] P. Craddy, H.J. Palin, K.I. Johnson, Comparative effectiveness of dipeptidylpeptidase- 4 inhibitors in type 2 diabetes: a systematic review and mixed treatment comparison, Diabetes Ther. 5 (1) (2014) 1-41.

[211] M. Nabeno, F. Akahoshi, H. Kishida, I. Miyaguchi, Y. Tanaka, S. Ishii, et al., A comparative study of the binding modes of recently launched dipeptidyl peptidase IV inhibitors in the active site, Biochem. Biophys. Res. Commun. 434 (2) (2013) 191-196.

[212] S. Shi, K. Kanasaki, D. Koya, Linagliptin but not Sitagliptin inhibited transforming growth factor- $\beta 2$-induced endothelial DPP-4 activity and the endothelialmesenchymal transition, Biochem. Biophys. Res. Commun. 471 (1) (2016) 184-190.

[213] Y. Zhao, L. Yang, Y. Xiang, L. Liu, G. Huang, Z. Long, et al., Dipeptidyl peptidase 4 inhibitor sitagliptin maintains $\beta$-cell function in patients with recent-onset latent autoimmune diabetes in adults: one year prospective study, J. Clin. Endocrinol. Metab. 99 (5) (2014) E876-E880.

[214] T. Awata, A. Shimada, T. Maruyama, Y. Oikawa, N. Yasukawa, S. Kurihara, et al., Possible Long-Term Efficacy of Sitagliptin, a Dipeptidyl Peptidase-4 Inhibitor, for Slowly Progressive Type 1 Diabetes (SPIDDM) in the Stage of Non-InsulinDependency: An Open-Label Randomized Controlled Pilot Trial (SPAN-S), Diabetes Ther. 8 (5) (2017) 1123-1134.

[215] L. Yang, H. Liang, X. Liu, X. Wang, Y. Cheng, Y. Zhao, et al., Islet function and insulin sensitivity in latent autoimmune diabetes in adults taking sitagliptin: A randomized trial, J. Clin. Endocrinol. Metab. (2021).

[216] X. Wang, L. Yang, Y. Cheng, P. Zheng, J. Hu, G. Huang, et al., Altered T-cell subsets and transcription factors in latent autoimmune diabetes in adults taking sitagliptin, a dipeptidyl peptidase-4 inhibitor: A 1-year open-label randomized controlled trial, J. Diabet. Investig. 10 (2) (2019) 375-382.

[217] I.K. Hals, H. Fiskvik Fleiner, N. Reimers, M.C. Astor, K. Filipsson, Z. Ma, et al. Investigating optimal $\beta$-cell-preserving treatment in latent autoimmune diabetes in adults: Results from a 21-month randomized trial, Diabetes Obes. Metab. 21 (10) (2019) 2219-2227.

[218] R. Buzzetti, P. Pozzilli, R. Frederich, N. Iqbal, B. Hirshberg, Saxagliptin improves glycaemic control and C-peptide secretion in latent autoimmune diabetes in adults (LADA), Diabetes. Metab. Res. Rev. 32 (3) (2016) 289-296.

[219] M. Maia Pinheiro, F. Moura Maia Pinheiro, L.L. Pires Amaral Resende, S. Nogueira Diniz, A. Fabbri, M. Infante, Improvement of pure sensory mononeuritis multiplex and IgG1 deficiency with sitagliptin plus Vitamin D3, Eur. Rev. Med. Pharmacol. Sci. 24 (15) (2020) 8151-8159.

[220] M. Maia Pinheiro, F.M. Maia Pinheiro, L.L.P. Amaral Resende, S.N. Diniz, A. Fabbri, M. Infante, 36-month follow-up of a pure sensory mononeuritis multiplex and IgG1 deficiency improved after treatment with sitagliptin and 
Vitamin D3, Eur. Rev. Med. Pharmacol. Sci. 25 (4) (2021) 1768-1769, https:// doi.org/10.26355/eurrev 20210225064.

[221] E. Mahabadi-Ashtiyani, V. Sheikh, S. Borzouei, I. Salehi, M. AlahgholiHajibehzad, Effect of Sitagliptin and Vitamin D3 on Secretion of IL- 6 and TNF- $\alpha$ Inflammatory Factors in Patients with Type 2 Diabetes, Avicenna J. Clin. Med. 25 (3) (2018) 134-141.

[222] E. Mahabadi-Ashtiyani, V. Sheikh, S. Borzouei, I. Salehi, M. AlahgholiHajibehzad, The increased $\mathrm{T}$ helper cells proliferation and inflammatory responses in patients with type 2 diabetes mellitus is suppressed by sitagliptin and vitamin D3 in vitro, Inflamm. Res. 68 (10) (2019) 857-866.

[223] Z. Telikani, V. Sheikh, A. Zamani, S. Borzouei, I. Salehi, M.A. Amirzargar, et al., Effects of sitagliptin and vitamin D3 on T helper cell transcription factors and cytokine production in clinical subgroups of type 2 diabetes mellitus: highlights upregulation of FOXP3 and IL-37, Immunopharmacol. Immunotoxicol. 41 (2) (2019) 299-311.

[224] S. Borzouei, V. Sheikh, M. Ghasemi, A. Zamani, Z. Telikani, Z. Zareighane, et al, Anti-Inflammatory Effect of Combined Sitagliptin and Vitamin D3 on Cytokines Profile in Patients with Type 2 Diabetes Mellitus, J. Interferon Cytokine Res. 39 (5) (2019) 293-301.

[225] N.S. Wahba, R.H. Abdel-Ghany, S.A. Ghareib, M. Abdel-Aal, A.E. Alsemeh, Vitamin D3 potentiates the renoprotective effects of vildagliptin in a rat model of fructose/salt-induced insulin resistance, Eur. J. Pharm. Sci. 144 (2020), 105196.

[226] E.M. Stein, E. Shane, Vitamin D in organ transplantation, Osteoporos. Int. 22 (7) (2011) 2107-2118.

[227] M. Infante, C. Ricordi, N. Padilla, A. Alvarez, E. Linetsky, G. Lanzoni, et al., The Role of Vitamin D and Omega-3 PUFAs in Islet Transplantation, Nutrients 11 (12) (2019).
[228] Q. Zhou, L. Li, Y. Chen, J. Zhang, L. Zhong, Z. Peng, et al., Vitamin D supplementation could reduce the risk of acute cellular rejection and infection in vitamin D deficient liver allograft recipients, Int. Immunopharmacol. 75 (2019), 105811.

[229] Yamada Y, Nishikawa S, Tanaka S, Hamaji M, Nakajima D, Ohsumi A, et al. CD26/DPP4 Inhibitor: A Novel Prophylactic Drug for Chronic Allograft Dysfunction after Clinical Lung Transplantation. The Journal of Heart and Lung Transplantation. Volume 39, Issue 4, Supplement, April 2020, Page S66.

[230] A. Bacigalupo, E. Angelucci, A.M. Raiola, R. Varaldo, C. Di Grazia, F. Gualandi, et al., Treatment of steroid resistant acute graft versus host disease with an antiCD26 monoclonal antibody-Begelomab, Bone Marrow Transplant. 55 (8) (2020) $1580-1587$.

[231] S.S. Farag, M. Abu Zaid, J.E. Schwartz, T.C. Thakrar, A.J. Blakley, R. Abonour, et al., Dipeptidyl Peptidase 4 Inhibition for Prophylaxis of Acute Graft-versus-Host Disease, N. Engl. J. Med. 384 (1) (2021) 11-19.

[232] P.J. Martin, Sitagliptin to Prevent Acute Graft-versus-Host Disease, N. Engl. J. Med. 384 (1) (2021) 70-71.

[233] T.S. Abdelaziz, A.Y. Ali, M. Fatthy, Efficacy and Safety of Dipeptidyl Peptidase-4 Inhibitors in Kidney Transplant Recipients with Post-transplant Diabetes Mellitus (PTDM)- a Systematic Review and Meta-Analysis, Curr. Diabetes Rev. 16 (6) (2020) 580-585.

[234] Pinheiro MM, Pinheiro FMM, Pizarro CB. Prolonged clinical remission of type 1 diabetes mellitus treated with sitagliptin and vitamin D3 could be related with changes in CD8+ lymphocytes count expressing CD26. Poster presented at the American Diabetes Association's 77th Scientific Sessions, San Diego, USA, 2017. 